\title{
Revision of the genus Teratolytta (Coleoptera: Meloidae)
}

\author{
Marco A. BOLOGNA and Andrea Di GIULIO
}

Dipartimento di Biologia, Università degli Studi "Roma Tre", Viale Marconi 446, 00146 Roma, Italy; e-mail: bologna@bio.uniroma3.it

Key words. Coleoptera, Meloidae, Teratolytta, key, catalogue, synonymy, new species, distribution, larval morphology, courtship

\begin{abstract}
The blister beetle genus Teratolytta, belonging to the tribe Lyttini, is revised and a classification is proposed. Two main sections of the genus - one including five groups of species and the other three groups - are tentatively defined. Four new species from Eastern and Southern Anatolia are described (T. carlae sp. n., T. dvoraki sp. n., T. monticola sp. n., T. taurica sp. n.), and a key to the 17 recognized species is proposed. A diagnosis of the species as well as taxonomic remarks are proposed, and a catalogue of localities is presented. In particular, Teratolytta tricolor (Haag-Rutenberg, 1880) comb. $\mathrm{n}$. is re-established as a distinct species, $T$. cooensis G. Müller, 1936 is confirmed as a synonym of $T$. gentilis (Frivaldszky, 1877), T. bytinskii Kaszab, 1957 as a synonym of $T$. senilis (Abeille de Perrin, 1895), and T. holzschuhi Dvořák, 1983 is proposed as a synonym of T. eylandti Semenow, 1894; some infraspecific forms are referred to the variability of $T$. gentilis and T. flavipes (Mulsant \& Rey, 1858). The first instar larva of $T$. gentilis is described and figured, and the sexual behaviour of this species is also briefly studied.
\end{abstract}

\section{INTRODUCTION}

Teratolytta was described by Semenow (1894) to include the species of Lytta Fabricius, 1775 previously classified by Escherich (1894) as "dives group", and a few additional species. Afterwards this genus was studied by Kaszab (1958, 1968a), who published a key and described new taxa, by Kryzhanovskij (1959) and Dvořák (1983), who added new species and subspecies, by Bologna (1994), who published new faunistic records and taxonomic remarks, and by Dvořák (1996), who proposed an updated key to the species.

It is a typical Turanian-Mediterranean element (sensu Vigna Taglianti et al., 2000), distributed from Tajikistan and Afghanistan, West to Anatolia and Balkans (North to Fruśka Gora and Banat). This genus belongs to the subfamily Meloinae, tribe Lyttini (Bologna, 1991; Selander, 1991), and it is phylogenetically related to Lytta and to the Lydina phyletic lineage (Bologna \& Pinto, 2001). Gupta (1978) erroneously included Teratolytta in the Mylabrini, a tribe clearly distinct by some adult and larval characters (Bologna, 1991; Bologna \& Pinto, 2001). Dvoř́k (1996) recently considered twelve species in the genus, but Dvoř́k (1983) and Bologna (1988, 1994) previously evidenced some possible synonymies or specific differences. According to the taxonomic novelties proposed here, 17 species are now recognized in the genus Teratolytta. No records on the ecology, ethology or preimaginal biology have been published, and the larval instars and hosts have been completely unknown, except for a description in Russian of $T$. pilosella with figures lacking detail and not useful for an advanced discussion (Zaripova, 1973).

Aims of this paper are: (i) to collect all available biological records and briefly describe the courtship of $T$. gentilis; (ii) to describe the triungulin of T. gentilis; (iii) to propose an updated key to the males of the species; (iv) to propose a tentative classification of the species; (v) to summarize faunistic knowledge in a commented catalogue, which includes the species diagnoses, taxonomic remarks and synonymies, and the descriptions of four new Turkish species.

\section{MATERIAL AND METHODS}

Some 478 adult specimens of all described species were examined, with at least one male of each species: Holotype and 5 paratypes of $T$. carlae; lectotype, 3 paralectotypes, and 180 other specimens of $T$. dives; holotype of $T$. dvoraki; 2 syntypes of $T$. eylandti, holotype of the synonym $T$. holzschuhi, and 42 other specimens; 96 specimens of $T$. flavipes; 1 type (probably the holotype) of $T$. gentilis, 1 type (probably the holotype) of the synonym $T$. cooensis, and 9 other specimens; 1 paratype and 16 other specimens of T. kaszabi; 3 paratypes and 3 other specimens of T. klapperichi; 2 specimens of T. kulzeri; holotype and 9 paratypes of $T$. monticola; 11 specimens of $T$. optabilis; 12 specimens of $T$. pilosella; 1 paratype of $T$. regina; holotype and 26 other specimens of $T$. senilis; holotype and 4 paratypes of $T$. taurica; 28 specimens of T. tricolor; 1 paratype and 1 other specimen of $T$. vanensis.

The examined material is preserved in the following collections (with associated acronyms reported in the text): $\mathrm{BMNH}=$ Natural History Museum, London; $\mathrm{CB}=$ Marco A. Bologna coll., Università "Roma Tre", Roma; C.Bruschi = Sandro Bruschi coll., Roma; $\mathrm{CD}=$ Miroslav Dvořák coll., Praha; C.Freude $=$ Heinz Freude coll., Falconara; C.Liberto $=$ Andrea Liberto coll., Roma; C.Migliaccio = Enrico Migliaccio coll., Roma; C.Moragues = Gérard Moragues coll., Marseille; C.Pinzari $=$ Giuseppe Pinzari coll., Roma; C.Probst $=$ Johann Probst coll., Wien; C.Saltini = Lucio Saltini coll., Modena; C.Scheuern $=$ J. Scheuern, Zoologischen Staatssammlung München; HNHM = National Museum of Natural History, Budapest; FSCA = Florida State Collection of Arthropods, Gainesville (the L.F. and R.B. Selander coll. of Meloidae); ISNB = Muséum de l'Institut Royal des Sciences Naturelles de Belgique, Bruxelles; $\mathrm{JP}=$ J.D. Pinto coll., University of California, Riverside; $\mathrm{MCNV}=$ Museo Civico di Storia Naturale, Venezia; MCSN = Museo Civico di Storia Naturale G. Doria, Genova; MGEN = 
Musée d'Histoire Naturelle de Genève; MNHN = Muséum National d'Histoire Naturelle, Paris; MRSN = Museo Regionale di Storia Naturale, Torino; MSNV = Museo Civico di Storia Naturale, Verona; MTR = Museo Tridentino di Storia Naturale, Trento; MUH = Zoological Museum of the University, Haifa; MUN = Museo Zoologico dell'Università "Federico II", Napoli; NHMW $=$ Naturhistorisches Museum, Wien; MZR = Museo Civico di Zoologia, Roma; PPT $=$ Plant Pests and Diseases Research Institute, Taxonomy Research Department, Teheran; SMNS $=$ Museum Stuttgart; ZMAS $=$ Zoological Museum of Academy of Sciences, St. Petersburg.

Ecological observations on the habitat preference, altitudinal range, host plants, etc., were obtained in the field personally (MAB) or by other Italian entomologists in Greece and in Turkey; other records have been obtained from the literature or from collection labels.

Preliminary observations of the male courtship of $T$. gentilis were performed in a small plastic box in the field, shortly after the sampling (Greece: Sporades Islands: Kos Island: Asklepeion, 23.iii.1989 M. Bologna et al. leg., CB), and in the laboratory, during a zoological expedition organized by the Italian National Council of Research in the Aegean islands on board of the Bannock ship. A very short courtship sequence was filmed with a Super 8 videocamera and subsequently analyzed. The reduced number of observed sequences could represent only a portion of a more complex behaviour incompletely detected.

A single female of $T$. gentilis from Asklepeion laid (25.iii.1989) three small masses of eggs in the rearing plastic box. First instar larvae hatched about three weeks later in Italy, at University laboratory, in three consecutive days (12.-14.iv.1989), and their behaviour was observed for one day. Eggs of T. gentilis were kept in a thermostatic cell with photoperiodic control under ca. $24-25^{\circ} \mathrm{C}$. The description of the first instar larva of $T$. gentilis is based on the following material, preserved in $70 \%$ ethanol, in the CB and JP: vials 59 (about 10 first instar larvae), 60 (about 20 first instar larvae), 61 (about 100 first instar larvae).

The morphological analyses were made by using a Leitz Laborlux S light microscope for first instar larvae cleared and mounted in Canada balsam on slides M56, M57, M64 (from vial 59), and a Philips XL30 scanning electron microscope for larvae mounted on stub 48 (from vial 61), after critical point dehydration and gold sputtering. The terminology of larval structures follows MacSwain (1956), Lawrence (1991), and Bologna \& Pinto (2001). Certain characters used in the larval chaetotaxy were adopted from notational conventions suggested by Selander (1990) and Bologna \& Di Giulio (2002).

\section{ECOLOGY}

Adults of Teratolytta occur in subxeric habitats. $T$. dives, T. flavipes, T. gentilis and T. senilis are primarily distributed in Mediterranean maquis and in pastures derived from thermophilic forests of oaks (e.g. Quercus coccifera) or conifers (particularly Pinus halepensis); other species as T. carlae, T. dvoraki, T. kaszabi, T. klapperichi, T. kulzeri, T. monticola, T. pilosella, T. regina, $T$. taurica, or $T$. tricolor are distributed in different steppe habitats at middle or high altitude. Some species were cited as pests of fruit cultivations (T. kaszabi, T. pilosella) (Kryzhanovskij, 1959; Pripisnova, 1987).

Species of this genus are apparently diurnal; one single specimen of T. eylandti was collected at Karakul (Uzbekistan), at light. Adult occurrence is restricted to spring and summer. The Mediterranean species are especially active in spring, and the Anatolian or Middle Asiatic steppe species both in spring and summer. The following adult occurrence is documented: $T$. carlae in the first half of May; T. taurica during May; $T$. gentilis from the second half of March to the middle of April, and in late May; $T$. kaszabi particularly from the middle of April to late May (about $83 \%$ of records), with a few records in the second half of June, the beginning of July and August; T. klapperichi at the beginning of April; T. regina in late April; T. kulzeri with scattered records in the second half of April and from late May to the end of June; T. pilosella, particularly from the second half of April to the middle of May ( $80 \%$ of records), with scattered records in the second half of March and beginning of April, of June and July; $T$. dives is active from late March to late June, especially in April; T. dvoraki in the second half of April; $T$. flavipes particularly from late May to the beginning of June (83\% of records) with scarce records in late April and beginning of May; T. monticola in the first half of June; T. senilis in March and April; T. tricolor in April and May; T. eylandti in May, with isolated records in the second half of March and late April; T. vanensis from late April to the end of May; T. optabilis from the beginning of April to the first half of June.

The altitudinal distribution varies from the sea level to more than $3000 \mathrm{~m}$ a.s.1. Two species can be considered lowland elements (T. gentilis: 10-1200 m a.s.l.; T. senilis: 50-350 $\mathrm{m}$ a.s.1.); several are mountain species, also present at high elevation (T. carlae: 1000-1800 m a.s.l.; $T$. dvoraki: 1500-1600 m a.s.1.; T. kaszabi: 1000-3000 m a.s.1.; T. kulzeri: 1500-2265 m a.s.1.; T. monticola: 1850-2400 m a.s.1.; T. pilosella: 1100 - at least $2000 \mathrm{~m}$ a.s.1.; T. regina: $2200 \mathrm{~m}$ a.s.1.; T. taurica: $1600-1700 \mathrm{~m}$ a.s.1.; T. vanensis: $2265 \mathrm{~m}$ a.s.1.); the remaining are hill species, which can be distributed also to middle elevation (T. eylandti: about 1000-1200 m a.s.1.; $T$ flavipes: 1000-1600 m a.s.l.; T. klapperichi: $1200-1500 \mathrm{~m}$ a.s.l.); or euryzonal (T. dives: $350-1600 \mathrm{~m}$ a.s.1.).

The few detailed records on adult food plant preferences evidenced the phyllophagy of some species on different host plant families, an uncommon ecological specialization among blister beetles known in some species of Lytta, as well as a feeding activity on flowers of both trees and herbaceous plants: (i) T. gentilis: in Kos (Sporades, Greece) on leaves and flowers of Sarcopotherium spinosum (L.) Spach (Rosaceae) (M. Bologna, obs.) and Calicotome villosa (Poir.) Link (Papilionaceae) (M. Daccordi, obs.). (ii) T. kaszabi: in Tajikistan on flowers of fruit trees of almond, peach, sweet cherry, wild myrobalan and apple (Rosaceae), but also on Ferula flowers (Apiaceae) (Pripisnova, 1987, for a review). (iii) T. pilosella: in Tajikistan on flowers of various cultivated fruit trees of the family Rosaceae, but also on Lonicera and Ferula (Pripisnova, 1987 for a review). (iv) T. dives: in Greece on Asphodelus (Brullé, 1832), Spartium junceum (E. Migliaccio, obs.), and on apple (Isaakidés, 1935). (v) T. senilis: in Israel on Quercus sp. and other plants (Kaszab, 1957; Finkel et al., 2002). (vi) T. monti- 


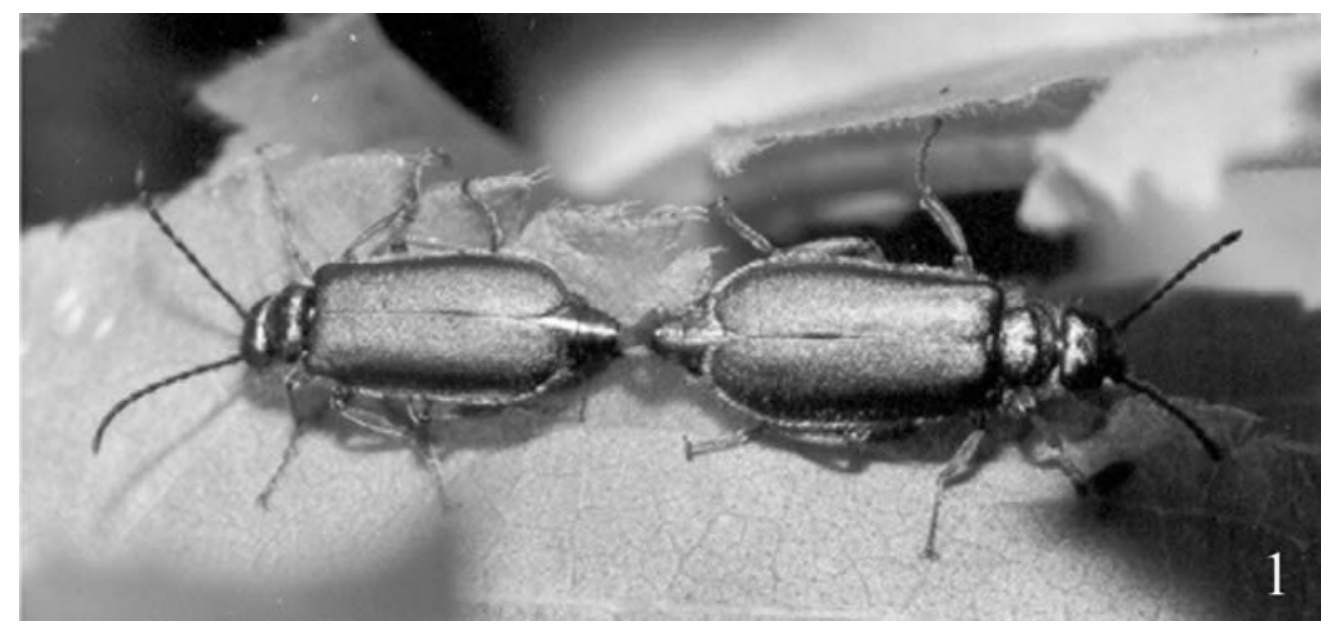

Fig. 1. Linear copulation of Teratolytta monticola (Photo Ph. Geniez).

cola: in East Turkey on Achillea (?) (Asteraceae) (Ph. Geniez, obs.).

No records on the larval development have been published; scarce data concerning $T$. gentilis are summarized in the Material and methods paragraph.

\section{BEHAVIOUR}

Courtship behaviour has never been studied in this genus. The great sexual dimorphism of middle tibiae, metasternum and metacoxae, might support the hypothesis of a complex courtship behaviour. Male specializations on several body structures as antennae, legs, or abdomen, have been evidenced in Meloidae, particularly in other Lyttini (see Bologna, 1991; Turco \& Bologna, 2004, for a review) in some of which the courtship involves these modified structures.

The available evidence on the courtship of a single species, $T$. gentilis, with male modifications on middle tibiae and tarsi, and on metatrochanters, does not support the hypothesis of a complex sexual behaviour. As previously indicated, a very short observation was carried out on $T$. gentilis in the Kos Island, and Turco \& Bologna (2005) reported a comparative synthesis of the courtship sequences of this species for comparison with other lyttine genera. As in other Meloinae genera, the courtship of $T$. gentilis includes a preliminary phase and a display phase. The brief posterior male preliminary phase includes a very fast palpal touching of the female abdomen apex and elytra, and antennae touching apex of female abdomen and elytra. The dorsal male display includes a lateral stretch of fore tibiae and raising of fore body, and antennal vibration over the female head; no manipulation of female legs with the modified male legs were noted. Both in T. gentilis (M. Bologna, obs.) and in T. monticola ( $\mathrm{Ph}$. Geniez, obs.) was evidenced a linear subphase of copulation on flowers (Fig. 1), as in other Meloinae genera. Also the assortative mating previously studied in the genus Lytta (Snead \& Alcock, 1985; Bologna \& Di Giulio, unpubl.) was noted: the larger males copulate with larger females, while smaller males stay alone and do not copulate.
No information on oviposition of this genus is available. That of $T$. gentilis was not observed, and eggs were probably laid at night, on the ground of the rearing box.

\section{DESCRIPTION OF TRIUNGULIN OF T. GENTILIS}

Habitus. Triungulin campodeiform (Figs 2-4); body elongate, slightly fusiform, slightly sclerotized. Body length about $1.7 \mathrm{~mm}$ (from abdominal apex to labrum); head length $0.23 \mathrm{~mm}$ (from occipital foramen to clypeolabral suture), maximum width $0.26 \mathrm{~mm}$; diameter of stemmata $24 \mathrm{~mm}$; epicranial stem $72 \mathrm{~mm}$; antennal length $69 \mathrm{~mm}$, terminal seta length $0.13 \mathrm{~mm}$; prothorax length $0.23 \mathrm{~mm}$, maximum width $0.33 \mathrm{~mm}$; abdominal length $0.93 \mathrm{~mm}$, maximum width (segments IV-V) $0.32 \mathrm{~mm}$, terminal setae length $0.23 \mathrm{~mm}$; diameter of spiracles: mesothoracic $12.3 \mathrm{~mm}$, abdominal I $10.7 \mathrm{~mm}$, abdominal II-VIII respectively from $10.5 \mathrm{~mm}$ to $8.7 \mathrm{~mm}$. Colour of membranous areas whitish, head, legs and sclerites light brown, distal half of mandibles dark brown. Terga of thorax and abdomen slightly sclerotized and entire; epipleura of thorax and abdomen completely fused with terga displacing the spiracles in a dorsal position; sterna of thorax and abdomen membranous, with the exception of the abdominal sternum IX and small areas around sternal setae. Cuticle reticulate with transverse polygonal meshes, more evident around terga, discal areas of terga smooth. Tergal setae short.

Head (Figs 5-6). Broader than long, greatest width at the level of temples; sides subparallel and broadly curved in posterior half; basal elevation absent; anterior margin subtruncate, slightly rounded laterally. Epicranial suture Y-shaped; basal half of frontal arms parallel, widely diverging apically to the antennal insertions. Stemmata small, circular, slightly convex, placed dorsolaterally. Frontoclypeal region with 16 setae; apex of frontoclypeus with one transverse row (frontoclypeal row, FCR) of three pairs of setae: $\mathrm{FCR}_{1}$ similar in length to $\mathrm{FCR}_{3}, \mathrm{FCR}_{2}$ longer than the others; one additional pair of setae present medially and slightly anterior to $\mathrm{FCR}$, between $\mathrm{FCR}_{1}$; one sensory pit between $\mathrm{FCR}_{2}$ and $\mathrm{FCR}_{3}$. Four pairs of sube- 


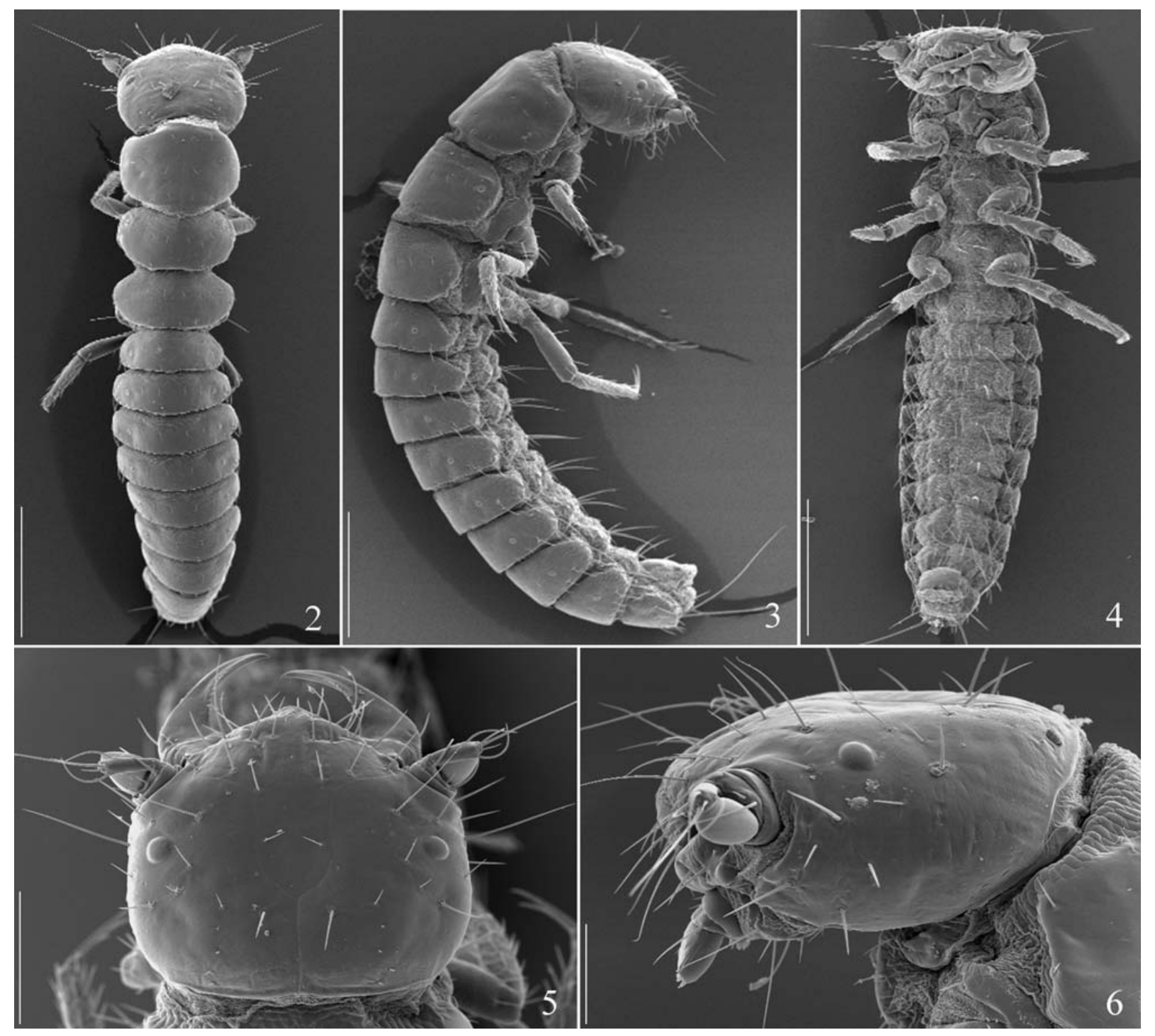

Figs 2-6: Teratolytta gentilis, first instar larva. 2 - dorsal view; 3 - right lateral view; 4 - ventral view; 5 - head in dorsal view; 6 - head in left lateral view. Scale bars $=250 \mu \mathrm{m}$ (Figs 2, 4); $200 \mu \mathrm{m}$ (Fig. 3); $100 \mu \mathrm{m}$ (Fig. 5); $150 \mu \mathrm{m}$ (Fig. 6).

qual setae posterior to FCR along a curved line paralleling the arms of the epicranial suture (setae 1-4 from the posterior to the anterior); one sensory pit present between setae 1 and 2. Basal part of each epicranial plate dorsally with four minute setae and one pit arranged in a longitudinal row (the basal row, BR) paralleling the basal stem of the epicranial suture; one pit posterolateral; nine pairs of setae and four pairs of sensory pits anterior to BR: one pair of setae close to the epicranial stem with one pair of pits placed anteriorly; one pair of shorter setae anterior to the BR; seven pairs of differently sized setae (including the ocular seta) and two pits encircling the stemmata; ocular seta and seta lateral to the stemma very long. Ocular sensory pit distinctly anterior to the stemma; ocular seta medial and slightly anterior to the ocular pit. Posterior half of ventral surface of each epicranial plate with one medial sensory pit. Anterior half with four pairs of setae and four pairs of sensory pits arranged as follows: two pairs of setae transversally lined at the level of cardo and two pairs of setae and three pits (one lateral and two medial, near mandibular acetabulum) placed anteriorly; one large pit placed medially, close to the base of the maxillae. Labrum (Fig. 12) transverse, subrectangular with curved sides, anteriorly bearing 22 setae of varying length transversally arranged in three rows: anterodorsal row with four pairs of long setae and one sensory pit; anteroventral row with four pairs of shorter setae; lateroventral row with three pairs of small setae. Antennae (Fig. 9) short, directed anterolaterally; antennomere I short, ring-like with one dorsal sensory pit; II distinctly asymmetrical, longer on the inner side where subequal to antennomere I, shorter on outer side, with three setae (two dorsal and one ventral), one minute dorsal seta and one dorsal pit medial to the others, near sensory appendix; sensory appendix on the outer side of antennomere II conical, hyaline and broad, positioned at 


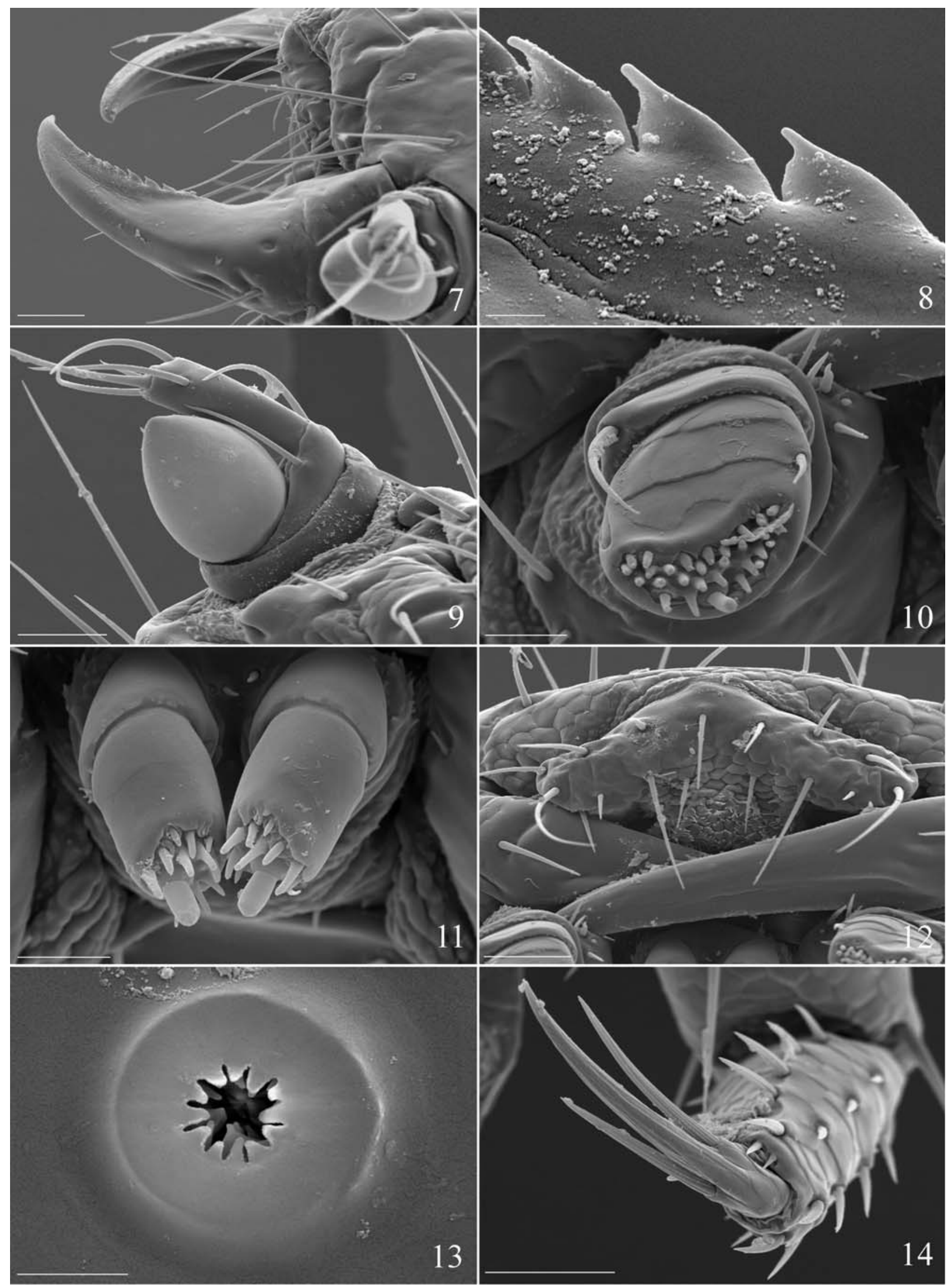

Figs 7-14: Teratolytta gentilis, first instar larva. 7 - left mandible, lateral view; 8 - detail of the left mandible; 9 - right antenna, lateral view; 10 - right maxillary palpus, anterodorsal view; 11 - labial palpi, anterodorsal view; 12 - labrum, frontal view; 13 mesothoracic spiracle; 14 - claw of left fore leg. Scale bars $=20 \mu \mathrm{m}$ (Figs 7, 9, 12, 14); $2 \mu \mathrm{m}$ (Fig. 8); $10 \mu \mathrm{m}$ (Figs 10, 11); $5 \mu \mathrm{m}$ (Fig. 13). 
apex, slightly ventral to the insertion of antennomere III, about as long as the latter; III slender and long, cylindrical, about as long as I and II together, with a long apical seta (about twice as long as the entire antenna), three long subapical setae, two lateral (one on outer and one on inner sides) and one dorsal; one minute seta near the base of apical seta. Mandibles (Fig. 7) conical-falcate, basal half broad and slightly sclerotized, apical half strongly sclerotized, narrowing and abruptly bending inward, ental margin medially keeled and with two edges: one ventral smooth; one dorsal with eight triangular, upcurved teeth (Fig. 8); outer margin of mandible with two setae, one sensory pit between them and one pit mesodorsally. Maxillae with stipes subquadrate and bearing two rows of setae: anterior row with two long setae and one medial pit; posterior row with two shorter setae and one pit between them; mala simple, lobiform, slightly protruding, with 7-8 spiniform setae; cardo transverse, subrectangular, with one short lateral seta; maxillary palpomeres I and II (Fig. 10) short, the first only slightly longer and wider; I with one ventral sensory pit; II with two subequal setae, one dorsal on the outer side and one ventral; III subrectangular, slightly narrower than II, dorso-ventrally flattened and spoon-like (slightly concave dorsally), about 1.8 times the length of I and II together, with one basal and dorsolateral seta (inner side) and one ventrolateral pit (outer side); apex of palpomere III convex and membranous, with a sensorial area composed of about 30 conical and subequal sensilla, one medial, larger and cylindrical with ring-like base, and one very small close to the medial; outer side of palpomere III with one slender digitiform sensillum. Gula without setae; submentum, mentum and prementum poorly sclerotized; submentum with two setae; mentum with two shorter setae and four pits; prementum with four setae, two short and basal and two longer and anterior. Labial palpomeres (Fig. 11) narrow and cylindrical, palpomere I slightly asymmetric (outer side longer) and 1 small ventral seta; palpomere II about twice as long as I, with a lateral pit and an apical circular slightly swollen sensorial area composed of ten conical and subequal sensilla, one larger medially placed and cylindrical with large ring-like base, and one very small close to the medial.

Thorax. Segments transverse, slightly broader than head; prothorax slightly wider than meso- and metathorax; margins of each thoracic segment rounded. Ecdysial line complete on pro- and mesonotum, incomplete posteriorly on metanotum. Anterior margin of pronotum membranous; each half of pronotum with twelve short setae and five pits symmetrically placed along three transverse, subparallel rows; anterior row (AR) with four setae and four pits; medial row (MR) irregular, with four setae and one pit; posterior row (PR) with four setae and two pits; prosternum with three pairs of medial setae arranged longitudinally and one pair anterior. Mesonotum narrower and slightly shorter than pronotum, similarly shaped, anteriorly sclerotized, with AR composed of four setae (very small and irregularly disposed); MR with six setae and one pit; PR with four setae and two pits; three pairs of medial setae on mesosternum, the anterior pair extremely short. Metanotum slightly narrower than mesonotum and subequal in length, more rounded on sides; setae of metathorax similar in number, position and relative dimensions to those of mesothorax.

Legs. Slender, coxa conical and elongate, with one small apical seta, four elongate medial setae, transversally arranged, gradually decreasing in length from basal to apical, three minute basal setae and one pit; trochanter with four apical setae and five pits; femur not enlarged in middle, slightly shorter than tibiotarsus, with six setae and one pit, the longest ventral femoral seta much shorter than femur; fore femora slightly more robust than the others; tibiotarsi and claws increasing in length from pro- to metathorax; tibiae slightly tapered at apex and with five longitudinal rows of 5-7 spine-like, moderately long setae; apical setae of tibiae slightly longer than apical width of tibiotarsus; claw (Fig. 14) conical-falcate, thin, acute and slightly curved at apex, with two setae of different length inserted at different levels near base (the apical distinctly longer than the basal).

Spiracles (Fig. 13). Round, internally papillate, with a small opening. Peritreme round and flat, slightly elevated and with 10-12 triangular projections encircling the opening. Mesothoracic spiracle anterolateral in position, abdominal spiracles medial in position, all spiracles distinctly dorsal and subequal in diameter.

Abdomen. Slightly fusiform, approximately 1.5 times as long as thorax; segments II-VI subequal, maximum width at IV; segment IX smallest and suboval; sternal abdominal area membranous except for sternum IX. Terga anterolaterally converging, with three transverse rows of setae on each half of tergum as follows: AR with three minute setae (four on tergum I) and one pit; MR with three setae at the level of the spiracle, two medial and one lateral (very long in segments II-VIII); PR with seven setae of various size and one pit. AR and MR of tergum IX with the same setation as segments II-VIII, PR composed of five elongate setae, longer than those of segments II-VIII, and one pair of very long setae (caudal setae), about as long as the last two abdominal segments combined. AR and MR of sterna I-IX with one pair of minute medial setae each, PR with four pairs of setae (three pairs on segment I), the two outer pairs (one pair on segment I) very long (except on segment IX). Segment $\mathrm{X}$ membranous, divided by a transverse anal fold in two parts: dorsal part semicircular with six extremely small setae transversally arranged, ventral part (pygopod) longitudinally divided in two lobes, moderately produced.

Larval features and relationships. Bologna \& Aloisi (1994) discussed some distinctive larval characters of $T$. gentilis and proposed a preliminary key to the larvae of lyttine genera, but this triungulin remained undescribed. Several characters of this species were also utilized for a cladistic analysis of the family Meloidae by Bologna \& Pinto (2001), who recognized the position of the genus within the tribe Lyttini, close to the Lydina phyletic lineage and to Lytta (Turco, Bologna \& Di Giulio, pers. obs.). 


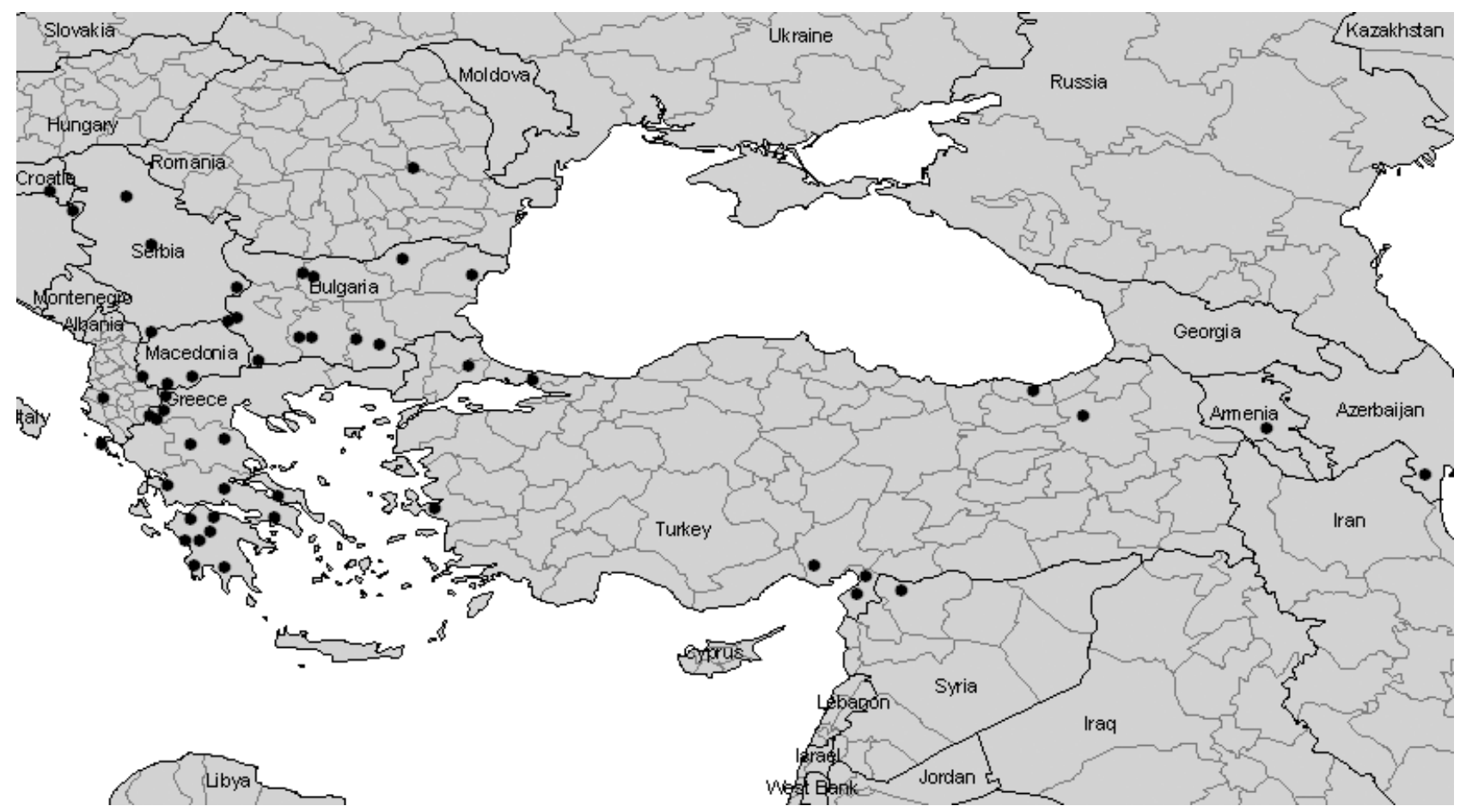

Fig. 15. Distribution of Teratolytta dives.

The first instar larva of Teratolytta is very similar to that of the genus Lytta F., 1775, particularly of its subgenus Poreospasta Horn, 1868, because of the shape of the maxillary palpi II-III, but differs from it by the shape of antennomere II, apically asymmetric and oblique and with the conical sensory appendix about as long as antennomere III, and by the scarce body sclerotization. The dorsal position of the mesothoracic spiracle is common to Lytta and Lydus Dejean, 1821, Alosimus Mulsant, 1857, and Prolytta Kaszab, 1959 (only in some species: Bologna \& Di Giulio, 2002). The large rounded first abdominal spiracle is common to the same genera plus Oenas Latreille, 1802 and Lydomorphus Fairmare, 1882.

\section{TAXONOMY}

\section{Genus Teratolytta Semenow, 1894}

Lytta of the dives-Gruppe, Escherich, 1894: 280.

Teratolytta Semenow, 1894: 533.

Type species. Cantharis dives Brullé, 1832 (by original designation).

Generic diagnosis. The genus Teratolytta is generally characterized by species with a marked sexual dimorphism. Several male characters do not represent generic synapomorphies but are present in most species of the genus, as the modifications of middle tibia (apex with a spine-like extension and sometimes with a spiniform tuft of modified setae), of metasternum (two tubercles with tufts of robust setae), or of metatrochanters (depressed and with an appendix). Except for these features, Teratolytta appears slightly distinct from Lytta, and only two autapomorphies can be recognized as diagnostic of the genus: lateral lobes of last male sternum with a long tuft of modified setae, and endophallus with an extremely large apical hook. Females are slightly distinct from those of the genus Lytta. Moreover, all Teratolytta species are characterized by shaggy pubescence and metallic green, blue or cupreous integuments, or bronze-black in a single species (T. pilosella).

The morphology of this genus was only insufficiently treated in literature: Kaszab (1959) described the wing venation, which is similar to that of other Lyttini, and Bologna \& Pinto (2001) figured the derived character of the male last abdominal sternum and the modified male tibiae of $T$. dives. Gupta $(1971,1978)$ described male and female external genitalia of $T$. dives, and transferred this genus from Lyttini to the tribe Mylabrini. This change is not supported by his discussion of the characters, which are erroneously interpreted, and contradicts several characters in adult and larval morphology of Mylabrini and Lyttini as discussed by Bologna (1991) and Bologna \& Pinto (2001). Male and female genitalia, except for the endophallic hook, show the typical lyttine morphology.

Classification and definition of species groups. In this paper we adopt a tentative classification of the species groups, primarily based on distinctive characters of each group. According to this classification, two sections are recognized on the base of the absence (section I), or presence (section II) of two tubercles on the metasternum, just posteriorly to the base of the middle legs. Eigth groups of species, four of them monotypic, are also defined according to other features. Even if not utilized for a cladistic classification, some characters are here evidenced as possible apomorphies when compared with their state in the whole family Meloidae.

Section I includes five species groups, two of which include more than one species (gentilis and klapperichi 
groups) and four are monotypic: (a) gr. carlae (T. carlae), (b) gr. gentilis (T. gentilis, T. taurica); (c) gr. kaszabi (T. kaszabi); (d) gr. klapperichi (T. klapperichi, T. regina, T. kulzeri); and (e) gr. pilosella (T. pilosella).

The species of this section have, as a primitive condition, the metasternum without tubercles and the pro- and mesotibiae with two spurs; one spur (derived condition) occurs only in the klapperichi group. Other variable features are: (i) apex of mesotibia not modified, or modified (as derived condition) in the gentilis group, and slightly modified in the pilosella group; (ii) hind trochanters variously shaped, and not modified at base, or with a basal appendix (as a derived condition); and (iii) two aedeagal hooks, or (as derived condition) only one hook or the distal one extremely reduced in the klapperichi group.

Section II includes three species groups, one of them monotypic: (a) gr. dives (T. dives, T. dvoraki, T. flavipes, T. monticola, T. senilis, T. tricolor); (b) gr. eylandti (T. eylandti, T. vanensis); and (c) gr. optabilis (T. optabilis).

The species in this section, which have the primitive condition of two spurs on pro- and mesotibiae, are primarily characterized by the derived condition of metasternum with tubercles apically covered by a tuft of modified setae. These species also have the apex of mesotibia markedly modified and hind trochanters with variously shaped appendix.

\section{Key to the species (males) of Teratolytta}

1 Metasternum with one tubercle on each side. . . . . . . . . 2

- Metasternum without tubercles. . . . . . . . . . . . . 10

2 Metasternal tubercles oval and elongate.......... 3

- Metasternal tubercles short and conical. . . . . . . . . . . . . 5 5

3 Protibiae ventrally not depressed, integuments opaque

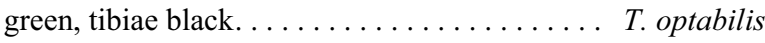

- Protibiae ventrally depressed, integuments shiny green or blue, tibiae at least partially orange-red. . . . . . . . . 4

4 Hind trochanter with a short triangular expansion, setose on inner margin, modified setae of last abdominal sternum as long as the latter, distal aedeagal hook close to the proximal one.............................. T. eylandti

- Hind trochanter with a long appendix, modified setae of last abdominal sternum longer than the latter, distal aedeagal hook separated from the proximal one. ....... T. vanensis

5 Hind trochanter orange-red with white long setae. . T. senilis

- Hind trochanter black, bearing white short setae. . . . . . . 6

6 Appendix of hind trochanter elongate and with apical tuft of long modified setae. ................... 7

- Appendix of hind trochanter short and without apical tuft of long modified setae. .................... 9

7 Appendix of hind trochanter with an outer curved expansion, nude at apex (Fig. 53); mesotarsomere I basally very large (Fig. 31); elytra with a middle longitudinal cupreous stripe; knee monochromatic red...... T. tricolor

- Appendix of hind trochanter not externally expanded at apex (Fig. 50); mesotarsomere I basally not very large (Fig. 26); elytra with or without a middle longitudinal cupreous stripe; knee black. . . . . . . . . . . . . . . 8

8 Mesotibial apex and mesotarsomere I as in Fig. 26, elytra green, usually with a middle longitudinal cupreous stripe ...

............................. dives

- Mesotibial apex and mesotarsomere I as in Fig. 28, elytra green or blue, never with a middle longitudinal cupreous stripe. . . . . . . . flavipes
9 Pronotum clearly transverse, elytra broad basally, with angulate humeri.................. T. monticola - Pronotum subtrapezoidal, elytra not so broad basally, with rounded humeri. ..................... T. dvoraki

10 Pro- and mesotibiae with one spur, mesotibial apex not modified. ......................... 11

- Pro- and mesotibiae with two spurs, mesotibial apex modi-

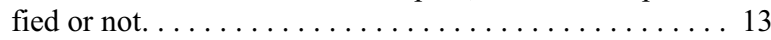

11 Head without postocular depression, last abdominal tergum modified as in Fig. 43 . . . . . . . . . . . . . . . . T. kulzeri

- Head with postocular depression, last abdominal tergum rounded or prominent, but not modified. . . . . . . . 12

12 Elytra with a middle longitudinal cupreous stripe, apex of metatibiae with black spiniform setae, last abdominal tergum prominent, apex of endophallic hook markedly prominent. .................. T. klapperichi - Elytra without a middle longitudinal cupreous stripe, apex of metatibiae without black spiniform setae, last abdominal tergum rounded, apex of endophallic hook normally rounded. ....................... T. regina

13 Head with a large depression posterior to eyes and extended dorsally on occiput, apex of protibiae gradually markedly enlarged, body black-bronze, with white setation grouped in tufts, mesotibial apex slightly modified as in Fig. 25, pronotum depressed on sides and with a deep longitudinal line. . $\ldots \ldots \ldots \ldots \ldots \ldots \ldots \ldots \ldots$. p. pilosella

- Head without postocular depressions, apex of protibiae almost cylindrical, body metallic green or blue, white setation regularly distributed, mesotibial apex may or may not be markedly modified, pronotum not depressed on sides and with longitudinal line moderately deep. .......... 14

14 Mesotibial apex modified as in Fig 20, hind trochanters with short appendix................. gentilis

- Mesotibial apex not modified, hind trochanters without appendix. ....................... 15

15 Parameres slender in the distal half, apex of endophallic hook markedly prominent, elytra green with a middle longitudinal cupreous stripe, pronotum pentagonal, knees redorange. ..................... kaszabi

- Parameres robust in the distal half, apex of endophallic hook normally rounded, elytra green or blue with or without middle longitudinal cupreous stripe, pronotum rounded on sides, knees black or red-orange. . . . . . . . . . 16

16 Mesotarsomere I slightly modified as in Fig. 21, mesotarsomere II with spiniform black setae, metatibial outer spur markedly enlarged at apex, not spoon-like, metatibiae slightly curved in the distal half, head surface shiny with more dispersed puncturation, knees red-orange. . . T. taurica Segment I of mesotarsi not modified as in Fig. 19, mesotarsomere II without spiniform black setae, metatibial outer spur spoon-like, metatibiae not curved in the distal half, head surface almost opaque with dense puncturation, knees black. ........................... carlae

\section{Commented catalogue and descriptions of new species}

For each species are indicated: the synonymies and the main combinations; the type locality and the type material, also for synonyms; a diagnosis and taxonomical remarks; the distribution, with the list of localities divided by states and districts, and with note on the collection where the material is preserved and/or literature citations. Four new species are described in this section. 


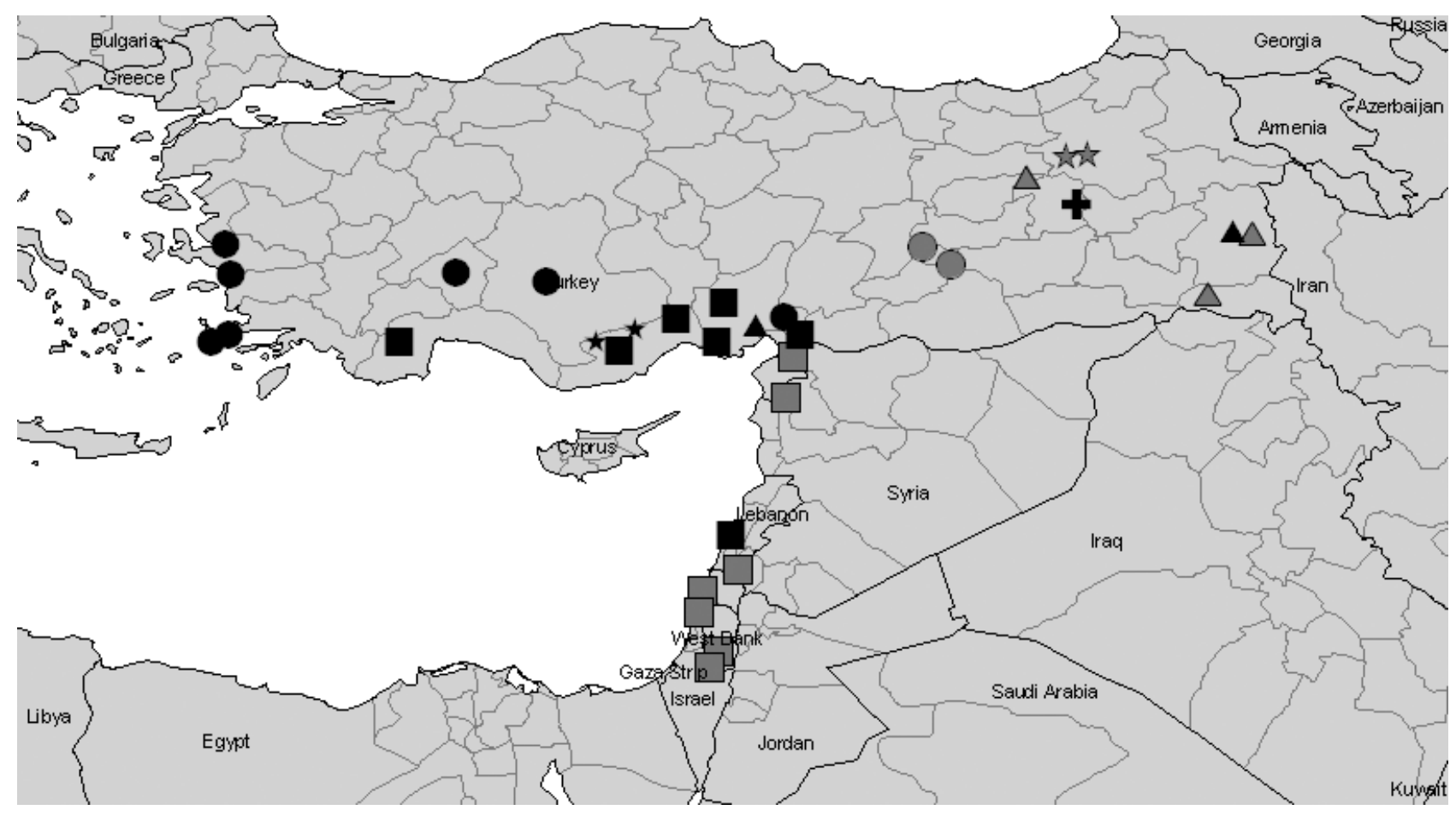

Fig. 16. Distribution of Teratolytta gentilis (black spots); T. flavipes (black squares); T. taurica (black stars); T. vanensis (black triangles); T. senilis (gray squares); T. carlae (gray spots); T. kulzeri (gray triangles); T. dvoraki (black cross); T. monticola (gray stars).

\section{Section I \\ Group carlae}

\section{Teratolytta carlae Bologna, sp. n.}

(Figs 19, 48, 55)

Diagnosis. Small sized. Body monochromatic metallic blue, or metallic bronze-cupreous and partially green; legs red with trochanter and knees black. Setation white, with scattered black setae, especially on the fore part of body. Head puncturation scattered, surface subopaque. Sexual dimorphism almost absent. Pro- and mesotibiae with two apical spurs in both sexes; pro- and metatibiae straight; parameres with robust apical lobes; penis with two apical hooks close to each other; endophallic hook slightly curved.

Description. Body metallic, entirely blue or bronzecupreous with green lateral margins and suture of elytra and base of pronotum; maxillary palpi orange-red as well as legs, except coxae, trochanters, apex of femora and base of tibiae black; mouthparts black, antennae subopaque black. Setation white with scattered longer black setae. Modified setae of male last abdominal sternum black. Body length (apex of mandibles to apex of elytra) 9.2-11.6 mm; head maximum width $2.0-2.1 \mathrm{~mm}$; pronotum length $1.5-1.6 \mathrm{~mm}$, width $2.0-2.1 \mathrm{~mm}$; elytral width greatest at posterior third $3.9-4.1 \mathrm{~mm}$.

Head short, subtrapezoidal, distinctly wider than long, maximum width at temples; lateral sides of head obliquely narrowed from base to eyes; frons slightly depressed at middle; mandibles short, robust and curved; temples convex without postocular depression; fore margin of labrum slightly emarginate; surface with mod- erately deep scattered punctures, surface between punctures subopaque; frontal sutures straight; maxillary and labial palpomeres slender; last maxillary palpomeres twice as long as penultimate; antennae extending to the basal third of elytra; antennomere I about twice as long as II, subequal to III; III-X elongate, cylindrical; III slightly shorter than the following; XI 1.5 as long as X, cylindrical, narrowing in the apical third; antennomeres I and II with long black setae.

Pronotum subpentagonal, maximal width at middle, slightly wider than long, longitudinally sligthly depressed at middle, transversally depressed along the base and with two small rounded depressions laterally on disk; pronotal punctures as on head. Scutellum large, subquadrate at apex. Elytra short, feebly convex, rounded at apex, without traces of venation, uniformly rugose, setation uniformly distributed. Metathorax without tubercles. Tibiae of all legs with two spurs, both slender and pointed on pro- and mesotibiae; spurs of metatibiae robust, inner pointed, outer spoon-like; male tibiae of all legs cylindrical, not modified at apex, with simple setation, mesotibiae without supplementary spine-like brush of setae (Fig. 19); male mesotarsomere I not modified (Fig. 19), slender and subconical, with simple setation as on mesotarsomere II; male metatrochanters simple (Fig. 48).

Last visible sternite of male abdomen emarginate, with modified setae as long as the entire sternite. Parameres (Fig. 55) robust and with robust apical lobes; penis with two apical hooks, close to each other, different in shape and size, distal markedly smaller than proximal; hook of the endophallus slightly curved, apically not acutely prolonged (Fig. 55). 


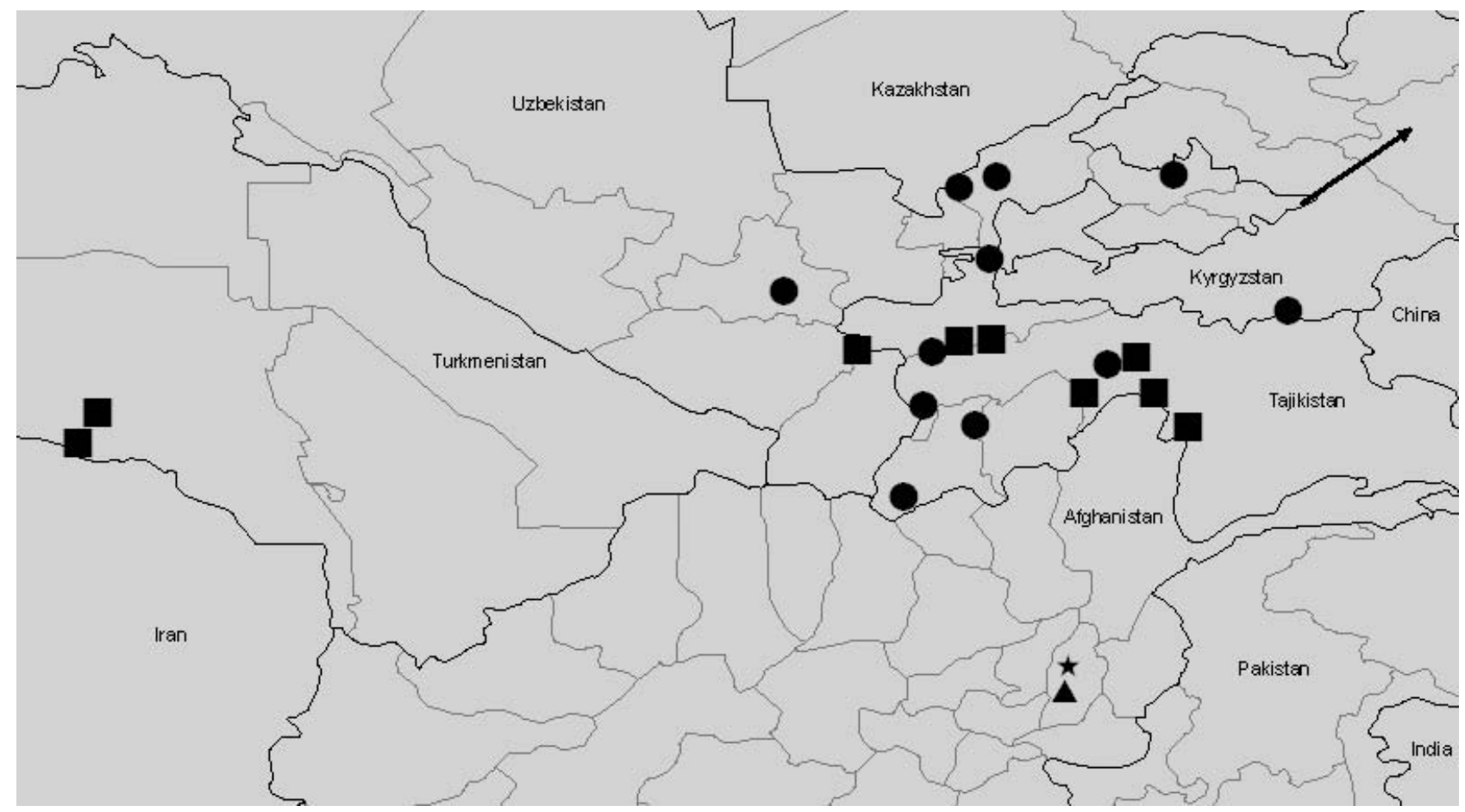

Fig. 17. Distribution of Teratolytta pilosella (spots; arrow indicates a disjunct record in Altaj Mts); T. klapperichi (stars); T. regina (triangle); T. kaszabi (squares).

Variation. Females with shorter antennae and last abdominal sternite not emarginate. Body metallic coloration of this species variable: some specimens are monochromatic blue, others from the same locality are bronze-cupreous with the ventral part of body, lateral margins and suture of elytra metallic green. The holotype and two female paratypes from the type locality (Malatya) have bronze-cupreous coloration; the other three male paratypes (one from the type locality, and two from the second locality) are blue.

Type material. Holotype $\delta(\mathrm{MNHN})$, "Turkey MalatyaTecde, Museum de Paris, ex coll. R. Oberthur". Paratypes, $10^{\hat{\sigma}}$ and 19 idem $(\mathrm{MNHN})$ and $19(\mathrm{CB}) ; 10$ (CB), "Türkei 1985, Nemrut Dagh, 11.V.1985, 1800 m, H. \& L. Freude"; 1 (CB), "Turchia-Adiyaman, Nemrut Daği m.1400-1600, 01-05-2000 leg. L. Saltini” (Fig. 16, gray spots).

Etymology. This species is named after Carla Marangoni, the first author's wife and curator of the Civic Zoological Museum of Rome, who collaborated in the field research of Teratolytta in southern Turkey and kindly accepted the lively life I offered to her.

Remarks. One male paratype from Malatya lacks antennomeres II-XI of both antennae, one female lacks antennomeres $\mathrm{X}-\mathrm{XI}$ of the right antenna and the fore right claw, another female lacks right antennomeres III-XI and right tarsomeres III-V and claw. One male paratype from Nemrut Dağ lacks antennomeres II-XI of both antennae.

Discussion. T. carlae appears to be the most primitive species of the genus, because of the almost complete absence of sexual dimorphism. As previously discussed, it belongs to the section I because of the lack of metasternite tubercles and it is similar to T. taurica because of the unmodified male mesotibiae, the presence of two spurs on pro- and mesotibiae, and the absence of postocular depression in male. Differs from T. taurica primarily by the unmodified male mesotarsomere I, and the male metatrochanters without small appendix, but also by the less shiny surface, the black apex of femur and base of tibia, the narrower pronotum, the lack of black robust setae on male mesotarsomeres I and II, the hind tibiae with outer spur smaller, and the endophallic hook slightly curved.

\section{Group gentilis}

\section{Teratolytta gentilis (Frivaldszky, 1877)}

Cantharis flavipes var. gentilis Frivaldszky, 1877: 136.

Cantharis dives var. violaceipennis Beauregard, 1890: 493.

Lytta dives var. coeruleipennis Escherich, 1894: 280 (erroneous citation of the Beauregard name).

Lytta dives var. gentilis, Escherich, 1894: 280.

Teratolytta dives var. gentilis, Borchmann, 1917: 106.

Teratolytta cooensis G. Müller, 1936: 91; Bologna \& Marangoni, 1990: 353; Bologna, 1994: 8.

Teratolytta gentilis, Kaszab, 1957: 230; Kaszab, 1958: 254; Kaszab, 1967: 538; Dvořák, 1996: 164.

Teratolytta gentilis ab. coensis (sic!), Kaszab, 1958: 254.

Type locality. [Turkey] "Ad Smyrnam” [= Izmir] (Frivaldszky, 1877). The type locality of the synonym $T$. cooensis is "Coo, Amhravi" (Müller, 1936).

Diagnosis. Body length: 11.5-16.5 mm. Green subolivaceous or metallic blue. Maxillary and labial palpi red as well as legs (except for coxa and trochanther), antennae black. Head without postocular depression. Metathoracic tubercles absent. Mesotibiae modified at apex (Fig. 20) with a spine-like brush of agglutinated setae without basal protuberance; two spurs on all tibiae; mesotarsomere I 


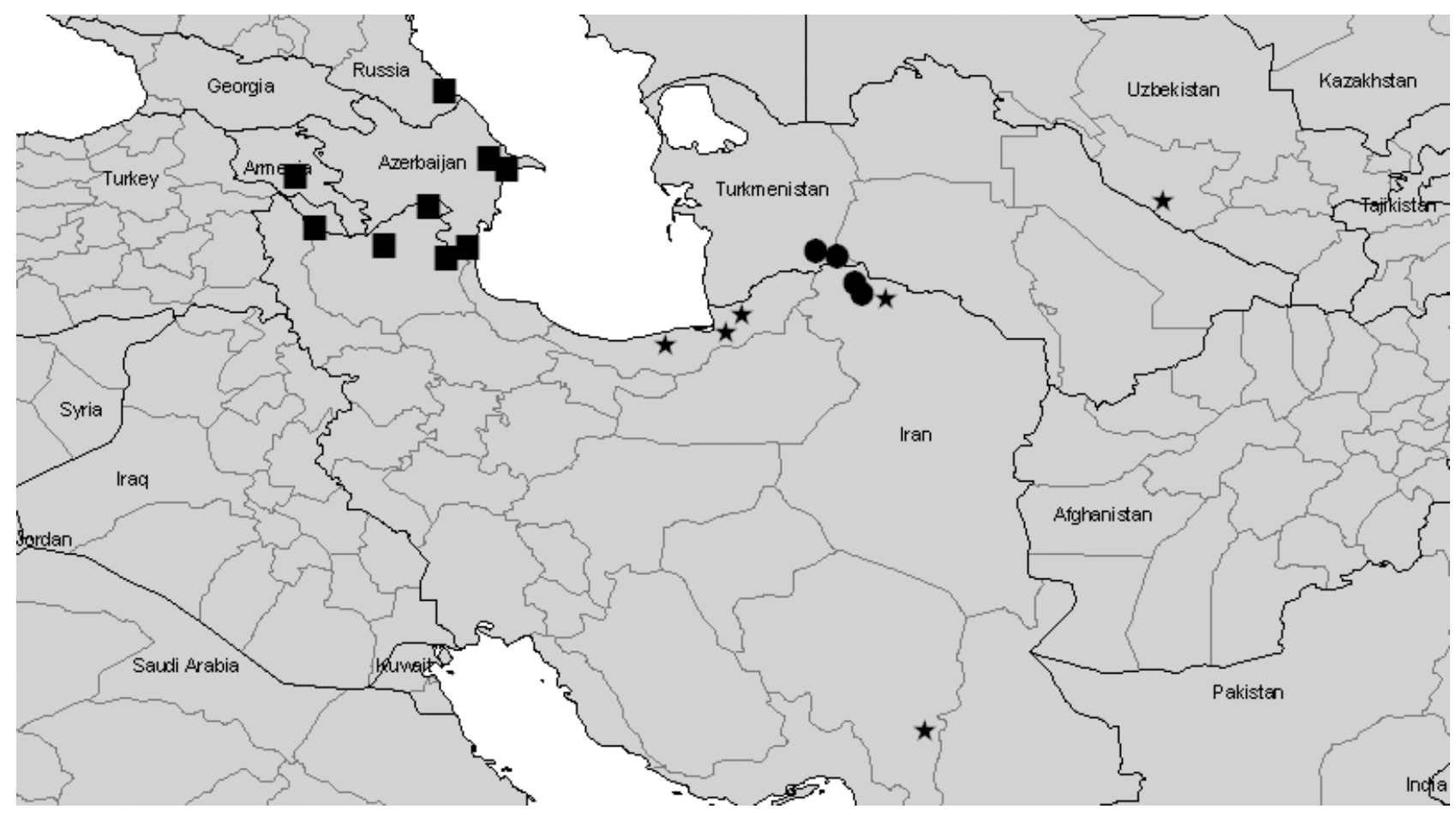

Fig. 18. Distribution of Teratolytta eylandti (spots); T. tricolor (stars); T. optabilis (squares).

longer than wide, subtrapezoidal; metatrochanters depressed and with a central carina, without laminiform appendix or tuft of setae. Last visible tergite of abdomen slightly emarginated at middle. Male genitalia as in Fig. 56; aedeagus with two hooks very close together, distal one small, endophallic hook slightly angulated, normally curved at apex. Female genitalia as in Fig. 71.

Taxonomic remarks. The colour variability of integuments (green or blue) produced erroneous interpretations of this species. As previously indicated, the holotype is blue as the single examined specimen from southern Turkey (Yarpus, CD); on the contrary, all other examined specimens from Sporades, Central and Western Anatolia (also from the type locality) are green. A similar colour variation is present in other Teratolytta species: T. carlae, T. flavipes, T. senilis. Müller (1936), followed by Bologna \& Marangoni (1990) and Bologna (1994), considered the green specimens from the Kos Island (Greece, Sporades) as a distinct species, named cooensis, but actually they represent only the most common chromatic form of this species.

Beauregard (1890) described the form violaceipennis of dives (erroneously cited as coeruleipennis by Escherich, 1894 and so quoted by Kaszab, 1958), which probably is referable to $T$. gentilis. Escherich (1896) and Kaszab (1958) erroneously assigned to T. gentilis also two chromatic forms (saphirina and semividua), which actually belong to $T$. flavipes (see below): three partially blue specimens of $T$. flavipes, erroneously identified as T.gentilis, from SE Turkey (Akbez, MNHN) and Syria (MNHN) were personally examined.

Type material. Single $\delta$ considered here as possible holotype, was examined at HNHM. It is blue, as indicated in the description (Frivaldszky, 1877); two other specimens from the same locality are positioned close to the type (HNHM), but probably they are not syntypes because they have green integuments.

One syntype of $T$. cooensis, considered here as possible holotype, was examined by Andrea Colla, Curator of the Trieste Museum (xi.2003). It is a male, lacking the left hind tarsus, and with three labels: "Isola Coo, Amhri, 22.3, XIII" (= 1935); Teratolytta n. sp. M. "(Giuseppe Müller's graphy); Teratolytta cooensis det. G. Müller 1947”. This last label was distinctly added 11 years after the description (Müller, 1936). According to the description, another female syntype is preserved in the "Ufficio Agrario Sperimentale di Rodi", but we do not have information about the present situation of this former institution of the Italian administration in Rhodes.

Distribution (Fig. 16, black spots). Greece: (Dodekanissa) Islands of Aegean See (Kaszab, 1958, 1967 sub Greek islands; Bologna, 1986). Kos (Bologna \& Marangoni, 1990, as T. cooensis); Kos, Amhravi (Müller, 1936, type loc. of T. cooensis; Bologna, 1994); Kos, between Kéfalos and Kamari (CB, MSNV; Bologna, 1994); Kos, Asklepeion (Bologna, 1994); Kos between Kéfalos and Agios Ioannis (CB; Bologna, 1994). Turkey: Asia Minor (Kaszab, 1958; Dvořák, 1996). (Izmir) Izmir (HNHM, MGEN; Frivaldszky, 1877; Escherich, 1894); between Meryamane and Selçuk (MGEN, det Z. Kaszab as T. dives). (Isparta) Eğirdir (HNHM). (Konya) Konya (HNHM). (Adana?) Yarpuz (CD) [in southern Turkey, Vilayet of Antalya, there is another small village with this name, on the road 695 , just $\mathrm{N}$ of Akseki, near the Irmasan Pass].

\section{Teratolytta taurica Bologna sp. $n$.}

(Figs 21, 57, 72)

Diagnosis. Middle sized. Body monochromatic metallic green or slight blue reflections, legs red with trochanter black, and apex of femora slightly infuscate. Setation white, with scattered black setae. Head puncturation scat- 

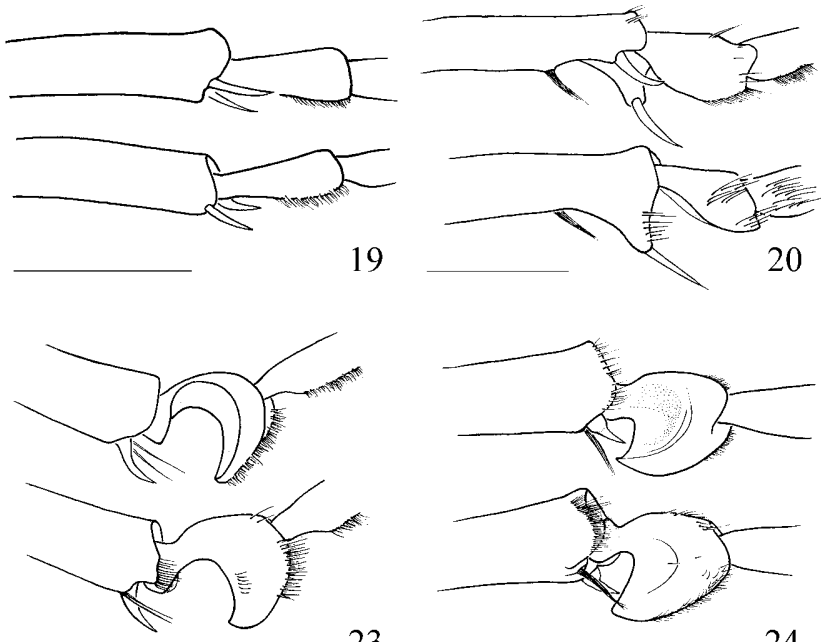

23

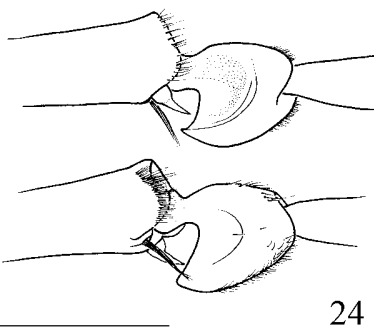

24
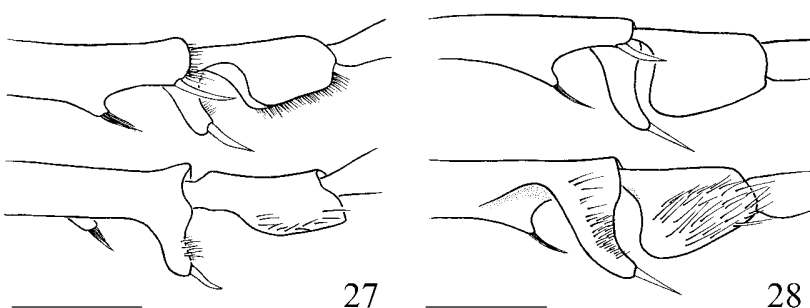

28

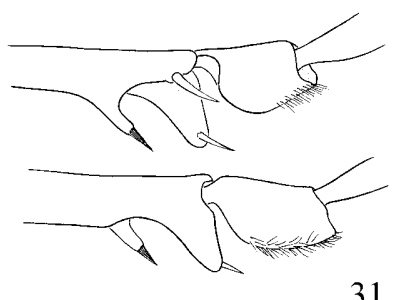

31

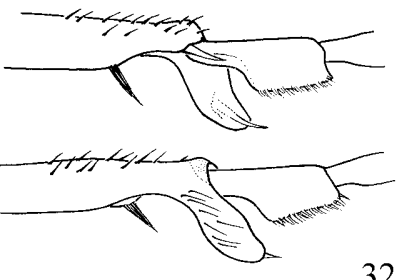

32
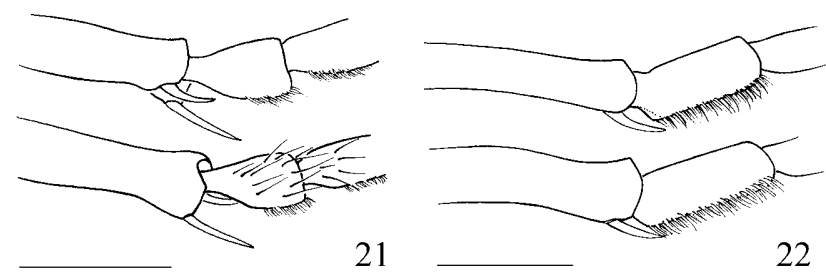

22
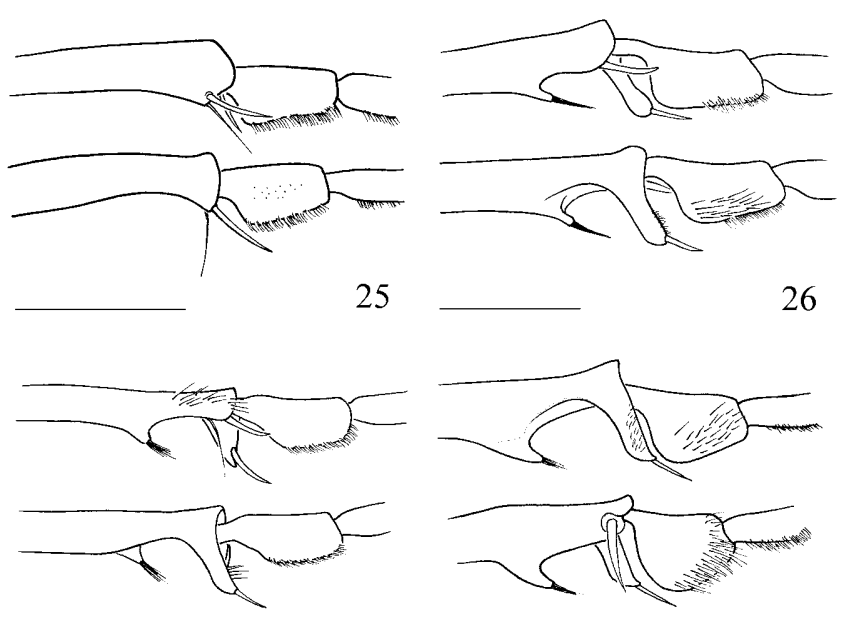

29

30

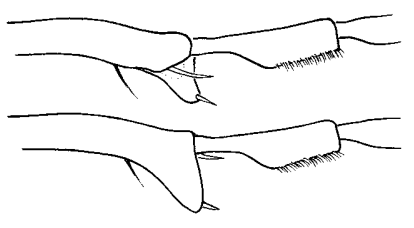

33

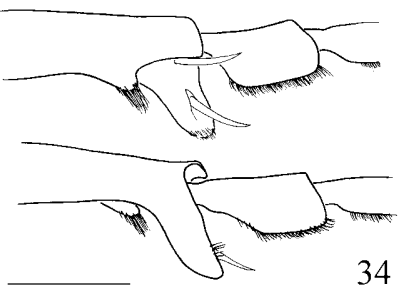

Figs 19-34. Male left mesotibial apex and mesotarsomere I, inner and lateral views. $19-$ T. carlae; $20-T$. gentilis; $21-T$. taurica; 22 - T. kaszabi; 23 - T. klapperichi; 24 - T. kulzeri; 25 - T. pilosella; 26 - T. dives; 27 - T. dvoraki; 28 - T. flavipes; 29 - T. monticola; $30-$ T. senilis; $31-$ T. tricolor; $32-$ T. eylandti; $33-$ T. vanensis; $34-$ T. optabilis. Scale bars $=1 \mathrm{~mm}$.

tered, surface shiny. Sexual dimorphism reduced: male mesotarsomere I enlarged and with modified black setae which are scarce but present also on II, male metatrochanters with a very small nude appendix; pro- and mesotibiae with two apical spurs in both sexes, outer metatibial spur very large; protibiae straight, metatibiae slightly curved on inner side; parameres with robust apical lobes; penis with two apical hooks close to each other; endophallic hook straight.

Description. Body metallic green or slightly blue; maxillary palpi orange-red as well as legs, except coxae and trochanters black, and apex of femora slightly infuscate; mouthparts black, antennae subopaque black. Setation white with scattered longer black setae. Modified setae of male last abdominal sternum black. Body length (apex of mandibles to apex of elytra) 12.0-12.2 $\mathrm{mm}$; head maximum width $2.5-2.6 \mathrm{~mm}$; pronotum length $1.9-2.0$ $\mathrm{mm}$, width $2.4-2.5 \mathrm{~mm}$; elytral width greatest at posterior third 4.5-4.7 mm.

Head short subtrapezoidal, distinctly wider than long, maximum width at temples; sides of head obliquely nar- rowed from base to eyes; frons slightly depressed at middle; mandibles short, robust and curved; temples convex without postocular depression; fore margin of labrum slightly emarginate; surface with scattered moderately deep punctures, surface between punctures shiny; frontal sutures straight; maxillary and labial palpomeres slender; last maxillary palpomeres twice as long as penultimate; antennae almost extending to middle of elytra; antennomere I about twice as long as II, subequal to III; III-X elongate, cylindrical; III slightly shorter than the following; XI 1.5 as long as X, cylindrical, narrowing in the apical third; antennomeres I and II with long black setae.

Pronotum transverse, almost hexagonal, maximal width at middle or just in front, clearly wider than long, longitudinally sligthly depressed at the middle, transversally slightly depressed along the base and laterally on fore third of disk; pronotal punctures as on head. Scutellum wide, subquadrate and depressed at apex. Elytra short, feebly convex, rounded at apex, with vague traces of venation, uniformly rugose, setation uniformly distributed. Metathorax without tubercles. Tibiae of all legs 

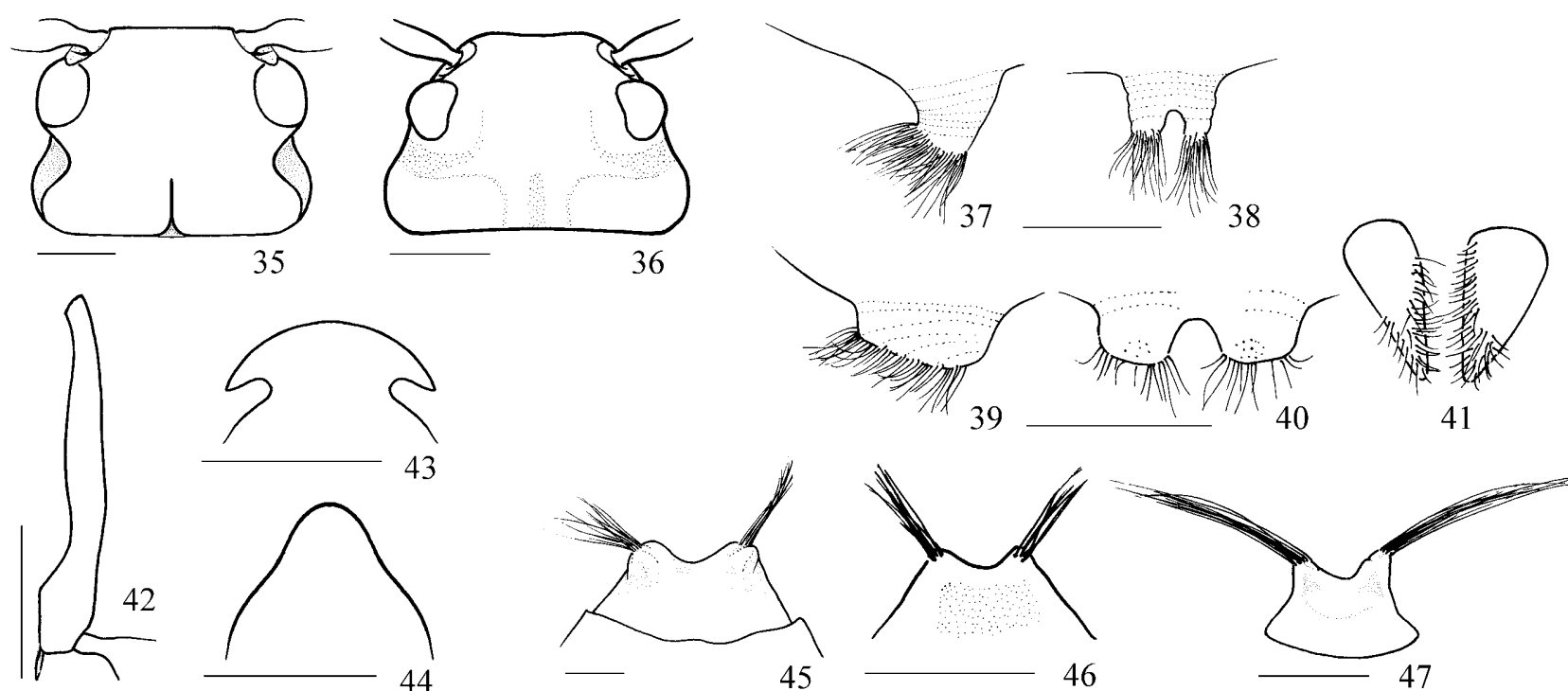

42
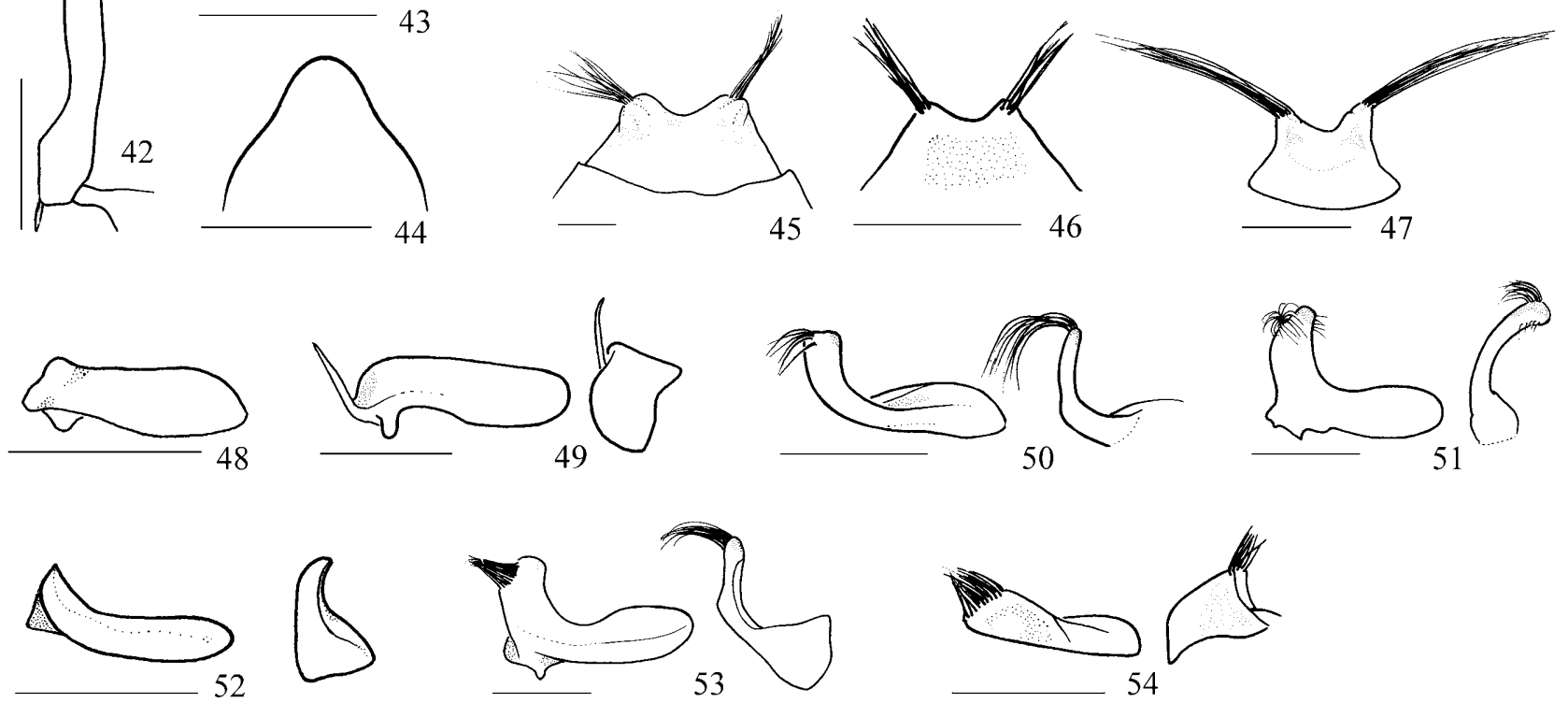

Figs 35-54: Male features. Head: 35 - Teratolytta klapperichi; 36 - T. pilosella. Mesosternal tubercles: 37, 38 - T. dives, right lateral and dorsal view; $39-41-T$. eylandti right lateral, dorsal and ventral view. Protibia: $42-T$. eylandti, outer right view. Last abdominal tergite: 43 - T. kulzeri; 44 - T. klapperichi. Last visible abdominal sternite: $45-T$. senilis; $46-T$. eylandti; $47-T$. vanensis. Metatrochanters in posterior and right lateral views: $48-T$. carlae (only in posterior view); $49-T$. kulzeri; $50-T$. dives; 51 - T. flavipes; $52-$ T. monticola; $53-$ T. tricolor; $54-T$. eylandti. Scale bars $=1 \mathrm{~mm}$.

with two spurs, both slender and pointed on pro- and mesotibiae; spurs of metatibiae robust, inner pointed, outer very large, subtruncate apically; male tibiae of all legs cylindrical, not modified at apex, with simple setation, mesotibiae without supplementary spine-like brush of setae, metatibiae slightly curved on inner side; male mesotarsomere I slightly modified (Fig. 21), subrectangular with a few robust black setae in the posterior half, tarsomere II not modified but with scarce black robust setae at base; male metatrochanters simple, only with a very small and nude appendix.

Last visible sternite of male abdomen emarginate, with modified setae as long as the entire sternite. Parameres (Fig. 57) robust and with robust apical lobes; penis with two apical hooks close to each other, different in shape and size, the distal one markedly smaller than proximal one; hook of the endophallus straght, not acutely prolonged apically. Female external genitalia as in Fig. 72.

Variation. The holotype and a male paratype have slight blue reflections on dorsal surface and abdomen. Females with shorter antennae, and last abdominal sternite non emarginated. Body length: 11.2-13.9 mm.
Type material. Holotype ô (CB), "Türkei 1985, Sertavul P., 5.V. 1600 m, H. \& L. Freude" (printed). Paratypes: 10 (CD) "Turkey m. Arsianköy, 27-28.V.1995 M. Johanides lgt." (printed); 2 ㅇ (CB, CD) "Turkey m. Arsianköy, 27.-28.V.1995 M. Johanides lgt." and, idem "Micka lgt. (printed)" (Fig. 16, black stars).

Etymology. The name of this species is derived from the Taurus Mts (Toros Daglari), the southern mountain chain extended along the Mediterranean coast of Turkey, rich in endemic species of Meloidae, where the new species is distributed.

Remarks. The holotype lacks the left antenna and both fore claws; one male paratype lacks hind left claw.

\section{Group kaszabi}

\section{Teratolytta kaszabi Kryzhanovskij, 1959}

Teratolytta kaszabi Kryzhanovskij, 1959: 857, Figs 1-3; Dvořák, 183: 442; Dvořák, 1996: 165.

Type locality. Tajikistan: Kvak in Varzob valley on the southern slope of the Hissar range (Kryzhanovskij, 1959).

Diagnosis. Body length: $11.8-17 \mathrm{~mm}$. Metallic bronzecupreous, with a green longitudinal stripe at middle of pronotum and along elytral suture and sides. Maxillary 

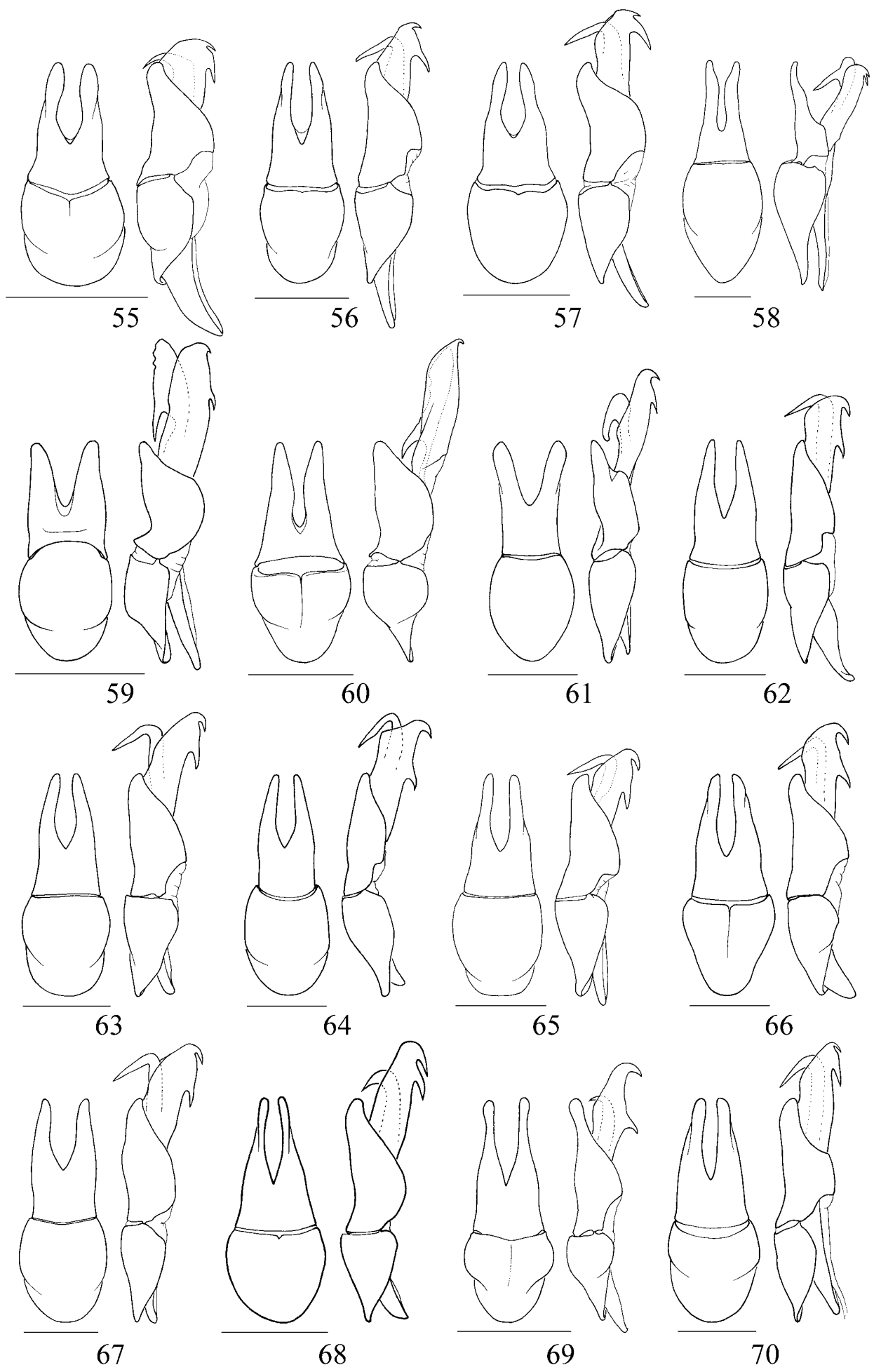

Figs 55-70: Male genitalia, ventral and right lateral views: 55 - Teratolytta carlae; $56-$ T. gentilis; 57 - T. taurica; $58-$ T. kaszabi; 59 - T. klapperichi; 60 - T. kulzeri; 61 - T. pilosella; 62 - T. dives; 63 - T. dvoraki; 64 - T. flavipes; 65 - T. monticola; 66 - T. senilis; $67-$ T. tricolor; $68-$ T. eylandti; $69-$ T. vanensis; $70-$ T. optabilis. Scale bars $=1 \mathrm{~mm}$.

and labial palpi and legs (except coxae) red, antennae black. Head without postocular depression. Metathoracic tubercles absent. Male mesotibiae not modified at apex and without a spine-like brush of setae (Fig. 22); metatibiae distinctly depressed on inner side, slightly curved; two spurs on all tibiae; mesotarsomere I and metatro- chanters not modified. Last visible tergite of male abdomen slightly emarginated at middle. Parameres (Fig. 58) extremely slender, lobes curved at apex, aedeagus with two hooks very close together and both apical, the distal one small, endophallic hook slightly angulated, 


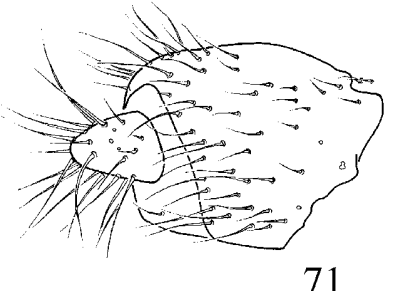

71

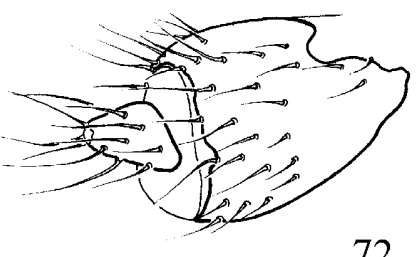

72
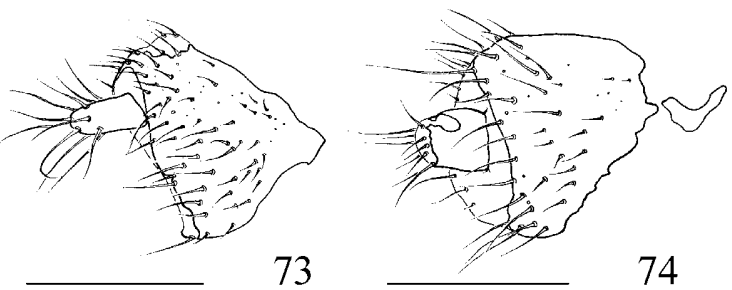

74
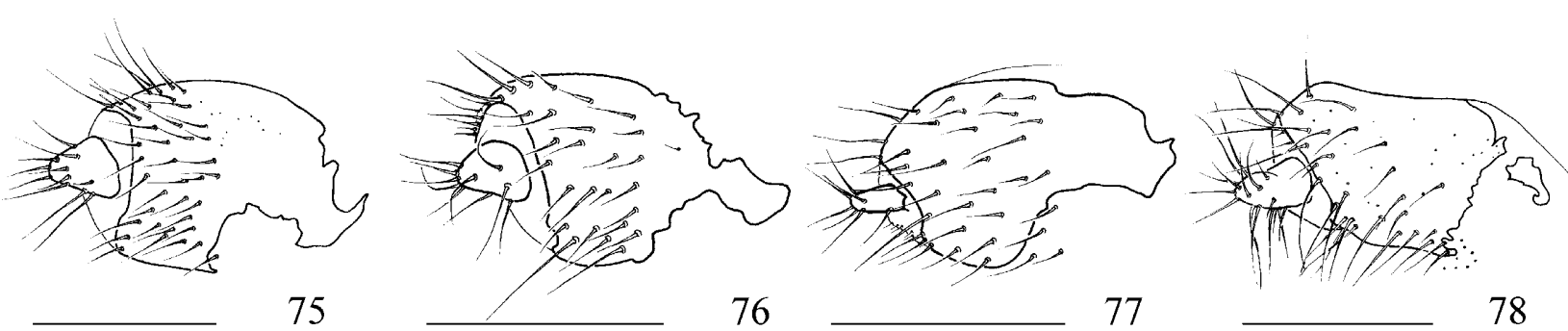

Figs 71-78. Female valvifer and stylus, right lateral views: 71 - Teratolytta gentilis; $72-$ T. taurica; $73-$ T. pilosella; $74-T$. dives; $75-$ T. flavipes; $76-$ T. monticola $; 77-$ T. eylandti; $78-$ T. optabilis. Scale bars $=0.5 \mathrm{~mm}$.

very long and slender, with anterior apex large and forming a keel.

Taxonomic remarks. Kryzhanovskij (1959) compared this species to $T$. regina because of the similar body coloration, but T. kaszabi has unmodified temples, two proand mesotibial spurs, and two aedeagal hooks. Dvořák (1983) discussed size (9.5-21 mm) and colour variability: the cupreous longitudinal stripe on elytra is more or less extended and more or less dark, similarly as in $T$. dives, $T$. regina, $T$. vanensis and $T$. carlae.

The Turkmenistan and part of the Uzbekistan citations of $T$. dives (cited as phalerata) refer to T. kaszabi, after the examination of material from these countries. $T$. kaszabi is easily distinguishable from $T$. dives and T. tricolor by the following characters: lack of sternal tubercles, middle legs slightly modified (Fig. 22), unmodified metatrochanters, pronotum trapezoidal rather than pentagonal, parameres slender and aedeagal hooks differently shaped (Fig. 58), wider bronze-cupreous elytral stripe, denser setation of the fore part of body.

Type material. Holotype $\delta$ allotype $q$ and $9 \hat{\delta} q$ paratypes, from Kvak in Varzob valley, $35 \mathrm{~km} \mathrm{~S}$ of Stalinabad [= Dushanbe], 2000 m, 22.v.1939, V. Gussakovskij leg.; 60 우 paratypes, from Kondora in Varzob valley, $1100 \mathrm{~m}, 10 .-20$. and 22.v.1939 V. Gussakovskij leg.; one paratype, Kondora 27.iv.1951, Brodinkova leg.; two paratypes, SE Tadjikistan, Tovil-Dora, 17.vi.1897, Kaznakov leg. (Kryzhanovskij, 1959). Holotype and other type specimens at ZMAS, not examined; one paratype examined in FSCA.

Distribution (Fig. 17, squares). Uzbekistan: W Hissar Mts, Tonhozdaya River, Chopuklu village (C.Probst); Syr Darja region, Shiraz env. (C.Probst). Turkmenistan: Turkmenistan (Reichardt, 1934, as phalerata). Ashkabad (Escherich, 1894, as phalerata); $60 \mathrm{~km} \mathrm{~N}$ Ashkabad (C.Probst). Tajikistan. Tajikistan (CB; Dvořák, 1996); Tovil-Dora (Kryzhanovskij, 1959); Hissars Mts: Javroz (CD; Dvořák, 1983); idem Romit (Dvořák, 1983); idem, Semiganc (CB, CD, C.Probst, MGEN; Dvořák, 1983); idem, Kvak ravine (Kryzhanovskij, 1959; Pripisnova, 1987); idem, Kondora (Kryzhanovskij, 1959); Darvaz: Tavildara,
Khobu-Robot Pass (C.Probst; Pripisnova, 1987); Khozratishokh Range, Ezgan (Pripisnova, 1987); Ganishov (C.Saltini).

\section{Group klapperichi}

\section{Teratolytta klapperichi Kaszab, 1958}

Teratolytta klapperichi Kaszab, 1958: 249; Dvořák, 1996: 163, Figs 6-7.

Type locality. [Afghanistan] "Nuristan, Basghultal" (Kaszab, 1958).

Diagnosis. Body length: 10.7-16.5 mm. Dark metallic green, with bluish reflections. Maxillary and labial palpi red as well as legs (except coxae, which are black), antennae black. Male genae with a deep impression extended from the postero-ventral to the postero-dorsal margin of eye (Fig. 35). Metathoracic tubercles absent. Male mesotibiae not modified at apex and without a spine-like brush of setae (Fig. 23); one spur on pro- and mesotibiae of male, two on metatibiae; male mesotarsomere I semilunar, wider than long, posterior margin convex, ventrally strongly depressed; male metatrochanters depressed, with a carina and a slender and very narrow apical appendix, hook-shaped, without setae; male metatibiae straight, with a large tuft of agglutinated long black and yellow setae. Last visible tergite of male abdomen conically projecting in the middle (Fig. 44). Parameres (Fig. 59) apically very wide, lobes almost indistinct, short and robust, aedeagus with two hooks subequal in size, separated, endophallic hook markedly angulated, apex large, forming a long keel.

Taxonomic remarks. Integuments usually completely metallic green, but some specimens have the elytra greenblue, or also head and pronotum are blue.

Type material. Holotype $\delta$ allotype $q$ and several $\delta \hat{q}$ paratypes (2 JP, 1 CB labelled "Paratype Teratolytta klapperichi m. det Kaszab 1956"; "J. Klapperich, Bashgultal 1200 m, Nuristan 10.4.53 Afghanistan", several of them at HNHM); "Nuristan, Basghultal, $1200 \mathrm{~m}, 8-10-15-17-20 . \mathrm{IV}$ [not indicated in the text!].1953 J. Klapperich"; several examined paratypes of both sexes, "Kamu, 1500 m, 26.IV.1953 J. Klapperich" (several of 
them at HNHM). A total of 266 paratypes are indicated in the original description without indications for each locality.

Distribution (Fig. 17, star). Afghanistan. Afghanistan (Kaszab, 1973; Dvořák, 1996). (Nuristan) Bashgul Valley (CB, CD, JP, HNHM; Kaszab, 1958)

\section{Teratolytta regina Kaszab, 1958}

Teratolytta regina Kaszab, 1958: 250; Dvořák, 1996: 164.

Type locality. [Afghanistan] "Nuristan, Kamdesch" (Kaszab, 1958).

Diagnosis. (From Kaszab, 1958, modified). Body length: 10.5-16.0 mm. Head, thorax and ventral surface bronze- or green-cupreous, elytral suture blue-violet and margins green or bronze-green; maxillary and labial palpi, and legs (except coxae, which are black) yellowred, antennae black. Male genae with a deep impression extended from the postero-ventral to the postero-dorsal margin of eye. Metathoracic tubercles absent. Mesotibiae not modified at apex and without a spine-like brush of setae; one spur on pro- and mesotibiae of male, two on metatibiae; male mesotarsomere I semilunar, wider than long, posterior margin convex, ventrally strongly depressed; male metatrochanters depressed, without carina and apical appendix; metatibiae straight, not modified, with normal setation. Last visible tergite of male abdomen slightly emarginated in the middle. Parameres apically wide, lobes almost indistinct, short and robust, aedeagus with two hooks subequal in size, close together, endophallic hook angulated, apex large and forming a keel.

Taxonomic remarks. Types of this species were only briefly examined (HNHM), but the validity of the species was confirmed. Colour variation was previously discussed (see T. kaszabi). T. regina differs from T. kaszabi primarily by the black knees, slender antennae, and the mesotarsomere I expanded.

Type material. [Afghanistan] Holotype $\hat{\delta}$, allotype $q$ and five paratypes of both sexes, Nuristan, Kamdesch, $2200 \mathrm{~m}$, 28.iv.1953 J. Klapperich leg. (HNHM); examined.

Distribution (Fig. 17, triangle). Afghanistan: Afghanistan (Kaszab, 1973; Dvoř́k, 1996). (Nuristan) Kamdesch (Kaszab, 1958).

\section{Teratolytta kulzeri Kaszab, 1958}

Teratolytta kulzeri Kaszab, 1958: 252; Dvořák, 1983: 441, Figs 1-4; Dvořák, 1996: 164, Figs 1-4.

Type locality. [Turkey] “Arm. Taurus, Moks” (Kaszab, 1958).

Type material. Holotype $q$ in the Zoologischen Sammlung des Bayerischen Staates in Munchen, not examined; 1 allotype o (HNHM) “Arm. Taurus, Moks, 28.V.1912 leg. H. Kulzer", examined (HNHM).

Diagnosis. Body length: 11.6-15.6 mm. Dark green metallic, with bluish reflections. Maxillary and labial palpi, and legs (except coxae and trochanthers) red, antennae black. Head without depressions. Metathoracic tubercles absent. Mesotibiae not modified at apex and without a spine-like brush of setae (Fig. 24); one spur on pro- and mesotibiae of male, two on metatibiae; male mesotarsomere I (Fig. 24) semilunar, wider than long, posterior margin convex, ventrally strongly depressed, with normal setation; male metatrochanters (Fig. 49) without carina and appendix; metatibiae normally shaped and setose. Last visible tergite of abdomen of male (Fig. 43) projecting at middle with an appendiculate semilunar expansion. Parameres (Fig. 60) apically very wide, lobes short and quite robust, aedeagus only with the distal hook, very small and apical in position, endophallic hook markedly angulated, apex large and forming a long keel.

Taxonomic remarks. This species is easily distinguishable from others of the same group at least by the last abdominal tergite expanded at apex (Fig. 43).

Distribution (Fig. 16, gray triangles). Turkey. Asia Minor (Kaszab, 1958; Kryzhanovskij, 1959; Dvořák, 1996). (Van) Moks near Çatak (HNHM; Kaszab, 1958, type loc.); Kusunkiran, East of Van (Kaszab, 1968a); Narlica env. (CB). (Hakkari) Est of Uludere, Süvarihalil geçidi (CD; Dvořák, 1983).

\section{Group pilosella}

\section{Teratolytta pilosella (Solsky, 1881)}

Cantharis pilosella Solsky, 1881: 259; Hauser, 1894: 23.

Lytta pilosella, Heyden, 1885: 281.

Lytta (Cantharis) pilosella, Dokhtouroff, 1890: 53.

Lytta pilosella var. albovillosa Escherich, 1894: 282.

Teratolytta pilosella, Borchmann, 1917: 107; Kaszab, 1958: 255; Dvořák, 1983: 444; Dvořák, 1996: 165, Fig. 9; Kolov, 2003: 164 .

Teratolytta pilosella pilosella, Kryzhanovskij, 1959: 858, Fig. 4. Teratolytta pilosella tadzhika Kryzhanovskij, 1959: 858, Fig. 5; Zaripova, 1973: 46.

Type locality. "Taschkent” (Solsky, 1881).

Diagnosis. Body length: 10-15.5 mm. Bronze-black or with dark green-bronze reflections, rarely metallic black. Maxillary and labial palpi black, legs red except the black base of femora, knees and tarsi, antennae dull black. Setation white with scattered black setae, denser ventrally and on head and pronotum, grouped in scattered tufts. Male genae (Fig. 36) with a large impression extended from the middle of posterior margin of eye to the middle of occiput, where both impressions converge in a longitudinal depression, posteriorly extended to vertex; frons depressed. Metathoracic tubercles absent. Male mesotibiae not modified, only slightly expanded internally (Fig. 25) without spine-like brush; two spurs on all tibiae; male mesotarsomere I (Fig. 25) longer than wide, subtrapezoidal, with normal setation; male metatrochanters without depression and carina. Last visible tergite of male abdomen conically projecting at middle. Parameres (Fig. 61) cylindrical, abruptly narrowed at apex, lobes slender and straight; aedeagus with subequal, spaced two hooks, endophallic hook markedly angulated, apically bent, apex normally curved. Female external genitalia as in Fig. 73.

Taxonomic remarks. Kryzhanovskij (1959) considered this species as polytypic and described the ssp. tadzhika, but Dvořák (1983) synonymized this subspecies with the nominate form. We agree with this synonymy because the examined Tajikistan specimens do not differ from those of other populations. According to Escherich 
(1894) the body colour, usually bronze-black, varies to olive or ligth green.

Type material. Types of the nominate form of this species, not examined, are probably preserved at ZMAS.

The holotype $\delta$, allotype $q$ and four paratypes of tadzhika, are labelled "Tadzhikistan, Kondara in Varzob valley, $1100 \mathrm{~m}$ 10-29.V.1939 V, Gussakovskij"; 15 other paratypes were collected in the same locality, "4.V.1940 A.E. Semenow leg." (Kryzhanovskij, 1959).

Distribution (Fig. 17, spots). Central Asia (Dvořák, 1996). Turkestan (Borchmann, 1917). Russia (Gorno-Altaj) Altai Mts (Escherich, 1894). Kazakhstan: Kazakhstan (Kolov, 2003). Uzbekistan: Tashkent (Heyden, 1885; Dokhtouroff, 1890; Escherich, 1894), Tashkent: Aktash (CB, C.Probst, MZR; Dvořák, 1983); idem: Chimgan (C.Probst; Dvořák, 1983); Pskent Hills, Takajangak (CD); Namangan (Heyden, 1885; Dokhtouroff, 1890; Escherich, 1894); Samarkand Mts, Serafshan (Hauser, 1894; Escherich, 1894). Tajikistan: Tajikistan (Dvořák, 1983). Chodshent (Escherich, 1894). Kondara ravine (CB; Semenow, 1951; Kryzhanovskij, 1959 type locality of ssp. tadzhika; Pripisnova, 1987); Hissar valley (Baeva, 1959); Babatag Range, Hissar fortress (Pripisnova, 1987); Varzob ravine (Pripisnova, 1987); Ramit ravine (Pripisnova, 1987); Dushanbe, Ramit (CD); Dushanbe botanical garden (C.Probst); Dushanbe, Tachtaul (CD); Khodzhaobigarm (Pripisnova, 1987); Vakhsh range, Shingdara ravine (Pripisnova, 1987); Kozratishokh Range, Ezgan (Pripisnova, 1987); Karatau Range, Akutal pass (Pripisnova, 1987); Aruktau Range, Gandzhina (Prispionova, 1987). Kirgizstan: Alai Mts (Heyden, 1888).

\section{Section II \\ Group dives}

\section{Teratolytta dives (Brullé, 1832)}

Cantharis dives Brullé, 1832: 232, Figs 7-8; Beauregard, 1890: 493.

Lytta phalerata E. Frivaldszky, 1837: 182, pl. 7, Fig. 12.

Cantharis phalerata, Mulsant \& Rey, 1858: 161.

Lytta vittata Kiesenwetter, 1861: 250 (nec Brullé, 1832).

Lytta dives, Reiche, 1859: 89; Escherich, 1894: 280 (pars) pls. 8-9.

Lytta dives var. excellens Escherich, 1894: 280.

Lytta (Teratolytta) dives, Kantardjeva, 1929: 42.

Teratolytta dives, Borchmann, 1917: 106 (pars); Kaszab, 1958: 254; Kryzhanovskij, 1959: 856; Bologna, 1994: 9; Dvořák, 1996: 165, Fig. 8.

Type locality. Cantharis dives: [Morée = Greece, Péloponnesos] "env. de Modou" (Brullé, 1832). Lytta phalerata: "Turquie" (E. Frivaldszky, 1837).

Diagnosis. Body length: 12.4-19.4 mm. Monochromatic green metallic or with a bronze-cupreous longitudinal stripe on middle of elytron and on genae. Maxillary and labial palpi, and legs (except metallic coxae and black throcanthers) red, antennae black. Head without postocular depressions. Male metathorax with conical tubercles. Male mesotibiae markedly modified at apex (Fig. 26), with a spine-like brush of agglutinated setae on a basal protuberance; two spurs on all tibiae; male mesotarsomere I (Fig. 26) longer than wide, subrectangular with black spiniform setae on inner side, II without modified setae; male metatrochanters (Fig. 50) depressed and with a central carina, with a great laminiform appendix bearing an apical tuft of setae. Last visible abdominal ter- gite of male slightly emarginated at middle. Parameres (Fig. 62) wide, short lobes, gradually narrowed; aedeagus with two subequal and spaced hooks, endophallic hook slightly angulated, curved at apex. Female external genitalia as in Fig. 74.

Taxonomic remarks. This species, widely distributed from the Balkans to Anatolia, was misinterpreted in the literature by several authors because of its colour variability. The nominate form was described from Morea (Greece) by Brullé (1832) as uniformly metallic green, but also striped specimens are present in the type series; the phalerata form was described by E. Frivaldszky (1837) from Thrace, and synonymized by Reiche (1859). This last phenotype is characterized by a longitudinal bronze-cupreous strip on the metallic green integument. Both forms are usually mixed in the populations in the whole range of the species, with an evident dominance of the striped form. The frequency of phenotypes in samples populations of $T$. dives with more than 5 specimens, confirms this dominance: Macedonia, Ohrid: 10 of 10; Macedonia, Jaratock E of Monastir: 11 of 11; Albania: 1 of 5; Greece, Souli: 15 of 16; Greece, Mega Spiliò: 10 of 15; Turkey, Istanbul: 4 of 5 .

According to the examined material, the citations from Iran, Uzbekistan and Turkmenistan refer to T. kaszabi and T. tricolor. Escherich (1894), in the first revision of this group, erroneously synonymized several taxa ( $T$. flavipes, T.eylandti, T. tricolor and T. gentilis) to T. dives. Also Kaszab (1958) erroneously synonymized $T$. flavipes to the nominate form of $T$. dives (see Bologna, 1994). Several authors adopted this erroneous synonymy and specimens of both species are usually mixed in the collections.

Beauregard (1890: 493, note 1) described the form violaceipennis (ISNB) from "Anatolie", as a variety of dives; this phenotype is characterized by violet elytra. Probably this form, erroneously cited as coeruleipennis by Escherich (1894: 280), should be referred to T. gentilis or to T. flavipes. The same author (Escherich, 1896: 28) referred to T. gentilis "Lytta"dives var. semividua Abeille de Perrin, 1895, but this form actually belongs to T. flavipes (see below).

Escherich (1894) doubtfully synonymized Cantharis vittata Brullé, 1832 to T. dives, but Bologna (1994) demonstrated that it is a synonym of Lytta vesicatoria moreana Pic, 1941.

Type material. Four damaged specimens are preserved at MNHN collection, the first of which has the labels "Cantharis dives Brullé Morée M. Brullé" (handwritten, white); "417" (handwritten, white). They represent syntypes of this species. One $\delta$ was designated as lectotype (M. Bologna des. 1988); another $\delta$ and $2 \%$ without labels but positioned just close to the lectotype, were designated as paralectotypes (M. Bologna des. 1988). All types lack antennae, and have elytra monochromatic metallic green or with indistinct narrow cupreous longitudinal stripe.

Distribution (Fig. 15). Balkans (Kaszab, 1958; Dvořák, 1996). Croatia: Slavonia (MCSN). Serbia and Montenegro: (Vojvodina) Fruska Gora, Syrmien (Kaszab, 1956 both nominate and phalerata forms; Kaszab, 1958; Tóth, 1973 both nominate and phalerata forms). (Serbia) Serbia (Kaszab, 1967); 
Drina (Kosanin, 1904); Ostra (Kosanin, 1904); Belgrade (Conev, 1958); Kragujevac (Conev, 1958), Pirot (Conev, 1958). Macedonia: Macedonia (C.Bruschi); Tetovo (Conev, 1958). Ohrid, Galicica (CB, MSNV, phalerata; Bologna, 1994); Bitola (Bologna, 1994); Bitola, Jaratock (MNHN, phalerata); idem: Holoven env. (MNHN); Marna Valley (MRSN); Varid (CB, phalerata; Bologna, 1994). Albania: Albania (MNHN, MSNV), both nominate and phalerata forms; Kaszab, 1967). Bregu, "Poggio Boschetto" (Schatzmayr, 1943), Terpan (Schatzmayr, 1943). Greece: Greece (HNHM, MUN, MZR phalerata; Gaubil, 1849; Beauregard, 1890; Kaszab, 1967; Iablokoff-Khnzorian, 1983; Bologna, 1986). (Corfu) Corfu (MNHN, MRSN; Bologna, 1994; phalerata); Corfu, Lakones (MRSN; Bologna, 1994; phalerata). (Florina) Florina (MNHN; Isaakidés, 1935; Bologna, 1994; phalerata); between Idroussa and Pérasma (C.Liberto; Bologna, 1994). (Kastoria) Kastoria (MNHN; Bologna, 1994). (Kozani) Morfi (CB, phalerata). (Larissa) Larissa (CD, phalerata). (Trikala) between Vlahava and Kalambaka (C.Probst). (Etolia-Akarnania) Etolia (Oertzen, 1886; Bologna, 1994), Akarnania (Legakis, 1990; Bologna, 1994). (Euboea) Euboea (HNHM, MGEN, phalerata); (Fthiotida-Viotia) Parnassos Mt. (MGEN, MTR, MSNV; Oertzen, 1886; Legakis, 1990; Bologna, 1994; phalerata). (Attica-Piréos) Attica (MNHN; Bologna, 1994). (Peloponnese) Peloponnese (MNHN; Brullé, 1832; Laporte de Castelnau, 1840; Kiesenwetter, 1861; Oertzen, 1886; both nominate and phalerata forms). (Achaia) Patras, Stavrodromi (CB, nominate form; Bologna, 1994); Kalavrita (C.Saltini); $6 \mathrm{~km} \mathrm{~N}$ of Mega Spiliò (CB, C.Saltini, phalerata). (Coritnth) Killini, between Kiato and Kastanea, env Souli (CB, C.Migliaccio, both nominate and phalerata forms); Corinth, Trikala (CB, phalerata; Bologna, 1994). (Ilia) Linaria (C.Moragues nominate form; Bologna, 1994); $20 \mathrm{~km} \mathrm{~W}$ Tripotama (C.Probst). (Archadia) Megalopoli Leontari (C.Probst). (Messinia-Lakonia) Kalamata (FSCA); Taigetos Mt. (Legakis, 1990; Bologna, 1994); between Maniaki and Flesias (C.Pinzari, phalerata; Bologna, 1994). Bulgaria: Bulgaria (Kaszab, 1967). (Kjustendil) Kjustendil (Kantardjeva, 1929). (Pernik) Cirka (Kantardjeva, 1929). (Sofia) Vitosha Planina (Kantardjeva, 1929). (Pleven) Sadovec (Kantardjeva, 1929). (Lovec) Lovec (Kantardjeva, 1929). (Pazardzhik) Pazardzhik (Kantardjeva, 1929). (Plovdiv) Plovdiv (Kantardjeva, 1929; Angelov, 1964); Ioakim Graevo (Kantardjeva, 1929). (Stara Zagora) Cirpan (Kantardjeva, 1929). (Haskovo) Haskovo (Kantardjeva, 1929). (Razgrad) Razgrad (Kantardjeva, 1929). (Varna) Varna (Kantardjeva, 1929). (Blagoevgrad) South Pirin Mts, Sveti Ilia hill, near Kalimantsi (C.Migliaccio). Two other unidentified localities were cited by Kantardjeva (1929). Romania: Romania (Kaszab, 1967). Russia or Ukraine: southern Russia (Escherich, 1894). Armenia: Armenia (Reichardt, 1934; IablokoffKhnzorian, 1983). Azerbaijan: Talysh (Iablokoff-Khnzorian, 1983: this record could be referable to T. tricolor). Turkey: European Turkey, Thrace and Rumelia (HNHM, FSCA, MGEN, MCSN, MNHN, phalerata; Frivaldszky, 1837; Waltl, 1838; Mulsant \& Rey, 1858; phalerata; Heyden et al., 1883; Beauregard, 1890; Escherich, 1894; Heyden et al., 1906; Kaszab, 1967). Anatolia (MNHN, phalerata; Escherich, 1894; Borchmann, 1917; Mader, 1927; Müller, 1936; Kaszab, 1956; 1958; 1968a; Kryzhanovskij, 1959; Iablokoff-Khnzorian, 1983; Dvořák, 1996); (Edirne) Gallipoli (FSCA, nominate form). (Istanbul) Istanbul, Kadi Keul (MZR); Istanbul (HNHM, MNHN, phalerata; Escherich, 1894); near Üskutar (MRSN; Escherich, 1897). (Trabzon) Halilli (HNHM). (Erzurum) Erzurum (MNHN, phalerata). (Izmir) Izmir (Escherich, 1894). (Adana) Adana (MNHN, phalerata); (Hatay) Akbez (MNHN, phalerata), Nur Daglari, Amanus Mts (MNHN, phalerata).
Anatolian localities not identified: Hadjin (Escherich, 1894); Sartari (MRSN). Syria: Syria (HNHM); Halep (MRSN).

\section{Teratolytta dvoraki Bologna sp. n. (Figs 27, 63)}

Diagnosis. Medium to large sized. Body monochromatic metallic green, legs red with trochanter and knees black. Setation white with scattered black setae particularly on fore part of body. Head puncturation scattered, surface shiny. Sexual dimorphism conspicuous: male metathorax with two short and conical tubercles; apex of male mesotibiae obliquely expanded and pointed, with an additional spine-like brush of setae, male mesotarsomere I enlarged and rectangular, with modified black setae, male metatrochanters with a short laminar appendix without apical setae; pro- and mesotibiae with two apical spurs in both sexes; pro- and metatibiae straight; parameres with robust apical lobes; penis with two apical hooks close to each other; endophallic hook straight.

Description. Body metallic, entirely green, without olivacous reflections; maxillary palpi orange-red as well as legs, except coxae, trochanters, apex of femora and base of tibiae black; mouthparts black, antennae subopaque black. Setation white with scattered longer black setae. Modified setae of male last abdominal sternum black. Body length (apex of mandibles to apex of elytra) $16 \mathrm{~mm}$; head maximum width $3.3 \mathrm{~mm}$; pronotum length $2.1 \mathrm{~mm}$, width $3.4 \mathrm{~mm}$; elytral width greatest at posterior third 6.5 $\mathrm{mm}$.

Head short subtrapezoidal, distinctly wider than long, maximal width at temples; lateral sides of head obliquely narrowed from base to eyes; frons slightly depressed at middle; mandibles short, robust and curved; temples slightly convex, without postocular depression; fore margin of labrum slightly emarginate; surface with scattered deep punctures, surface between punctures shiny; frontal sutures straight; maxillary and labial palpomeres slender; last palpomere twice as long as penultimate, longer than third; antennae extending to the basal third of elytra; antennomere I about twice as long as II, slightly shorter than III; III-X elongate, cylindrical; III slightly shorter than the following; XI 1.5 as long as X, cylindrical, narrowing at apical third; antennomeres I and II with long black setae.

Pronotum pentagonal, maximal width at middle, wider than long, longitudinally sligthly depressed at middle, slightly depressed in the middle of base; pronotal punctures as on head. Scutellum large, subquadrate at apex. Elytra short, feebly convex, rounded and more flattened at apex, without traces of venation, uniformly and densely rugose, sparsely setose except on margins. Metathorax with 2 short and conical tubercles. Tibiae of all legs with 2 spurs, both slender and pointed on pro- and mesotibiae; spurs of metatibiae robust, inner pointed, outer spoon-like; male pro- and metatibiae cylindrical, not depressed or curved, with simple setation; mesotibiae enlarged at apex, with an inner suboblique and pointed laminiform expansion and a few slightly modified setae at apex, and with a spine-like brush of setae beyond the middle of the tibia (Fig. 27); male mesotarsomere I modified, subrectangular with spiniform black setae on inner 
margin (Fig. 27), mesotarsomere II not modified and without black setae; male metatrochanters with a short and nude laminiform appendix.

Last visible sternite of male abdomen emarginate, with modified setae as long as the entire sternite. Parameres (Fig. 63) robust and with very short robust apical lobes; penis with two apical hooks, close to each other, different in shape and size, distal smaller than proximal; hook of the endophallus straigth, not acutely prolonged apically.

Type material. Holotype ơ (CD), "Anatol. Or., Bugleu Pass, Solhau, 1500-1600 m, 30.IV.1989, W. Heinz leg." (Fig. 16, black cross).

Etymology. This species is named after Miroslav Dvořák, a Czech entomologist working on blister beetles, who has published a couple of papers on the genus Teratolytta. The single specimen of the new species was found in the very interesting material of his collection that he kindly sent to me for study.

Remarks. The holotype lacks last tarsomeres and claws in both fore legs.

Discussion. T. dvoraki clearly belongs to the same group of $T$. dives by the shape of metathoracic tubercles and mesotibiae. It is easily distinguishable from the nominate form of $T$. dives by the shape of the nude and short appendix of metatrochanters. The same characters, as well as the elytral coloration, separate it from $T$. tricolor (with a cupreous strip) and $T$. flavipes (more olivaceous). Differs from $T$. senilis because of the pentagonal pronotum and the black trochanters. It appears more similar to T. monticola, which has a wider pronotum, usually infuscate legs, wider humeri, and the metabia slightly depressed on inner side.

\section{Teratolytta flavipes (Mulsant \& Rey, 1858)}

Cantharis flavipes Mulsant \& Rey, 1858: 163.

Lytta dives (pars), Escherich, $1894: 280$.

Lytta dives var. flavipes, Abeille de Perrin, 1895: xxv.

Lytta dives var. semividua Abeille de Perrin, 1895: xxv.

Lytta gentilis var. semividua, Escherich, 1896: 28.

Lytta dives var. saphirina Abeillle de Perrin, 1895: xxv.

Teratolytta dives (pars), Borchmann, $1917: 106$.

Teratolytta dives var. flavipes, Kaszab, 1958 : 254.

Type locality. Unknown (Mulsant \& Rey, 1858).

Diagnosis. Body length: 11.2-16.4 mm. Monochromatic metallic green. Maxillary and labial palpi, and legs (except metallic coxa and black throcanther) red, antennae black. Head without postocular depressions. Male metathorax with conical tubercles. Male mesotibiae markedly modified at apex (Fig. 28) with a spine-like brush of agglutinated setae on a basal protuberance; two spurs on all tibiae; male mesotarsomere I (Fig. 28) longer than wide, subtrapezoidal and, as well as segment II, without spiniform setae; metatibiae not enlarged and with normal setation; male metatrochanters (Fig. 51) depressed and with a central carina, with a great laminar appendix apically bearing a tuft of setae. Last visible tergite of male abdomen slightly emarginated at middle. Parameres (Fig. 64) wide, short, in lobes gradually narrowed, aedeagus with two subequal and spaced hooks, endophallic hook slightly angulated, curved at apex. Female external genitalia as in Fig. 75.
Taxonomic remarks. As previously noted, this species was misinterpreted in the literature and synonymized with T. dives (e.g., Escherich, 1894; Abeille de Perrin, 1895; Wellman, 1910b; Kaszab, 1958) and it was firstly revalidated by Bologna (1988). The integuments coloration of $T$. flavipes varies from complete metallic green (nominate form) to partially (form semividua: head and pronotum black, elytra blue), or completely metallic blue (form saphirina). Specimens of the form semividua were examined from SE Turkey (Taurus: Namrun, Camliyayla; Nur Dağlari) mixed with the nominate form. Also the form saphirina was collected together with the nominate one in SW Turkey, Akbez, as well as another specimen (identified as "Halosimus bicolor Haag"), showing traces of a cupreous longitudinal stripe, similarly to $T$. dives of the phenotype phalerata.

This species differs from the monochromatic nominate form of $T$. dives by: (i) the lateral expansion of mesotibiae longer and larger (Figs 28 and 26, respectively); (ii) the mesotibial inner apex slightly differently inclined (Figs 28 and Fig. 26, respectively); (iii) mesotarsomere I distinctly larger and with modified setae (Figs 28 and 26, respectively); (iv) the shape of trochanters (Figs 51 and 50 , respectively); (v) the shape of male genitalia (Figs 64 and 62 , respectively).

Type material. The description of this species is based on a single ot (collection Godart) probably preserved in the Lyon Museum (Mulsant \& Rey, 1858) and not examined.

In MNHN, one $q$ as holotype of the saphirina form. It has the following labels: "Syrie Amanus C. D. 1891" (printed); TYPE (red, printed); "v. saphirina Ab. "(M. Pic graphy ?);" Museum de Paris Delagrange coll. M. Pic "(white, handwritten/printed); "Holotype Lytta flavipes var. saphirina Abeillle de Perrin, M. Bologna det. 1985" (red, handwritten), "Teratolytta flavipes (Mulsant) M. Bologna det. 1985" (white, handwritten/printed).

In MNHN, some specimens of the semividua, probably syntypes, were also examined: one $q$ labelled " flavipes var. semividua" (Abeille de Perrin graphy), "Akbès, Delagrange", with blue pronotum and elytra, and one $\delta$ labelled "Akbès" (Pic-Delagrange coll.).

Distribution (Fig. 16, black squares). Turkey: Anatolia (MNHN). (Antalya) Elmali (C.Probst). (Içel) Namrun, Çamliyayla (CB, CD, C.Probst, C.Saltini, HNHM, MSNV; Kaszab, $1968 \mathrm{a}$ as dives var. saphirina); Aydinlar (C.Saltini); Gülek Taurus (HNHM); Tekir Taurus (HNHM). (Adana) Adana (ISNB, MNHN, MGEN det. Winkler as T. dives); Çatalan (C.Probst). (Antiochia) Akbez (MNHN, identified also as dives or gentilis). Syria: Syria (MNHN). Lebanon: Lebanon (MCSN); Saida (MNHN)

\section{Teratolytta monticola Bologna sp. $n$.}

(Figs 1, 29, 52, 65, 76)

Diagnosis. Medium sized to large. Body monochromatic metallic green, legs red, more or less infuscate (particularly tarsi), with trochanter and knees black. Setation white, with scattered black setae particularly on fore part of body. Head puncturation scattered, surface shiny, frontal depression broadley extended to occiput. Sexual dimorphism distinct: male metathorax with two short and conical tubercles; apex of male mesotibiae (Fig. 29) 
obliquely expanded and pointed, with an additional spinelike brush of setae, male mesotarsomere I enlarged and rectangular, with modified black setae, male metatrochanters (Fig. 52) with a laminar appendix without apical setae; pro- and mesotibiae with two apical spurs in both sexes; protibiae straight, male metatibiae slightly depressed on inner side; parameres with robust apical lobes; penis with two apical hooks close to each other; endophallic hook straight.

Description. Body metallic, entirely green, without olivacous reflections; maxillary palpi infuscate, orange-red, as well as legs which are infuscate with almost dark tarsi, but coxae, trochanters, apex of femora and base of tibiae black; mouthparts black, antennae subopaque black. Setation white with scattered longer black setae. Modified setae of male last abdominal sternum black. Body length (apex of mandibles to apex of elytra) $8.4-18 \mathrm{~mm}$; head maximum width $2.0-2.4 \mathrm{~mm}$; pronotum length $1.7-2.0$ $\mathrm{mm}$, width $2.4-2.5 \mathrm{~mm}$; elytral width greatest at posterior third 4.9-5.2 $\mathrm{mm}$.

Head short subtrapezoidal, clearly wider than long, maximal width at temples; lateral sides of head obliquely narrowed from base to eyes; frons distinctly depressed in the middle, this depression, even if slightly, extends posteriorly as a wide parallel area, almost to the occiput; mandibles short, robust and curved; temples slightly convex, without a postocular depression, only sligtly flattened; fore margin of labrum almost straigth; surface with scattered deep punctures, surface between punctures shiny; frontal sutures straight; maxillary and labial palpomeres slender; last maxillary palpomere twice as long as penultimate, longer than third; antennae extending to basal third of elytra; antennomere I about twice as long as II, slightly shorter than III; III-X elongate, cylindrical; III slightly shorter than the following; XI 1.5 as long as X, cylindrical, narrowing at apical third; antennomeres I and II with long black setae.

Pronotum transversally subtrapezoidal, clearly wider than long, maximal width at middle, sligthly longitudinally depressed at middle and transversally at base; pronotal punctures as on head. Scutellum large, subquadrate at apex. Elytra short, wide on humeri, slightly convex, rounded at apex, without traces of venation, uniformly and densely rugose, sparsely setose except on margins. Metathorax with two short and conical tubercles. Tibiae of all legs with two spurs, both slender and pointed on pro- and mesotibiae; spurs of metatibiae robust, inner pointed, outer spoon-like; male protibiae cylindrical, metatibiae slightly depressed on inner side, both with simple setation; mesotibiae enlarged at apex with an inner subperpendicular and pointed laminar expansion, with few modified black setae at apex (Fig. 29), a spine-like brush of setae beyond middle of tibia; mesotarsomere I of male modified (Fig. 29), subrectangular with spiniform black setae on inner margin, mesotarsomere II not modified and without black setae; male metatrochanters with a moderately long nude laminar appendix (Fig. 52).

Last visible sternite of male abdomen emarginate, with modified setae as long as the entire sternite or slightly longer. Parameres (Fig 65) robust and with very short robust apical lobes; penis with two apical hooks, close each to other, different in shape and size, distal smaller than proximal; hook of the endophallus straigth, not acutely prolonged apically. Female external genitalia as in Fig. 76.

Variation. Some paratypes have less shiny integuments. Females have shorter antennae, and last abdominal sternite not emarginate.

Type material. Holotype $\widehat{\delta}(\mathrm{CB}), 5 \hat{\sigma} q$ paratypes $(\mathrm{CB}, 10$ MNHN), "Turquie, $16 \mathrm{Km}$ avant [= Est] d'Erzurum, $21 \mathrm{Km}$ après [= West] de Pasinler, route E80-100, 1854 m, 6.VI.2002, $\mathrm{Ph}$. Geniez and A. Teynié leg., $39,9643^{\circ} \mathrm{N}-41,4103^{\circ} \mathrm{E}$ [WGS-84]". 10 paratype (CB), "Turquie, NG.13180 Turquie, Erzurum, $8 \mathrm{~km}$ au sud du col du Palandöken, Direction Tekman (Sud de Erzurum), (2400 m), 39 $46^{\prime} \mathrm{N}, 41^{\circ} 20^{\prime} \mathrm{E}$, 5.VI.2001 Ph. Geniez leg." (Fig 16, gray stars).

Etymology. The name of this species is derived from its adaptation to mountain habitat.

Remarks. One male paratype lacks the antennomeres IV-XI of right and VIII-XI of left antenna, and tarsomeres IV-V of both fore tarsi; one male paratype lacks tarsomeres IV-V of left fore tarsi; one male paratype lacks antennomeres II-XI of right antenna, the complete right and tarsomeres $\mathrm{IV}-\mathrm{V}$ of left foretarsus; one male paratype (MNHN) lacks antennomeres III-XI of both antennae and of left metatarsus; one female paratype lacks tarsomeres III-V of right metatarsus; the male paratype from Palandöken lacks the left middle tarsus.

Discussion. $T$. monticola clearly belongs to the $T$. dives group because of the shape of metathoracic tubercles and mesotibiae. It is closely related to $T$. dvoraki and differs from other species in the group by the same characters. Differences from $T$. dvoraki include the shape of pronotum, which is distinctly wider and more trapezoidal, head depressions, infuscate legs, wider humeri, and the metatibia slightly depressed on inner side.

Ecological remarks. The type locality is a basaltic plateau, characterized by humid mountain vegetation, and all the specimens have been collected on an undetermined Asteraceae, probably belonging to the genus Achillea (Geniez, pers. comm., 2003). In the second locality, several specimens, forming an aggregation, have been examined (N. Gompel, pers. comm., 2001).

\section{Teratolytta senilis (Abeille de Perrin, 1895)}

Lytta senilis Abeille de Perrin, 1895: xxiv.

Teratolytta bytinskii Kaszab, 1957: 230.

Teratolytta senilis, Borchmann, 1917: 107; Kaszab, 1958: 254; Dvořák, 1983: 444; Dvořák, 1996: 165.

Type locality. "Haute Syrie: Akbès" (Abeille de Perrin, 1895). Akbez is a village of SE Turkey, Hatay Province, along the eastern slope of the Amanus Mts, on the Turkish-Syrian border. The type locality of T. bytinskii is "Israel, Daphne oaks" (Kaszab, 1957).

Diagnosis. Body length: $17 \mathrm{~mm}$. Monochromatic green metallic. Maxillary and labial palpi, and legs (including coxae and trochanters) red, antennae black. Head without postocular depressions. Male metathorax with conical tubercles. Male mesotibiae markedly modified at apex 
(Fig. 30) with a spine-like brush of agglutinated setae on a basal protuberance; two spurs on all tibiae; male mesotarsomere I (Fig. 30) longer than wide, subtrapeizoidal and, as well as metatarsomere II, without spiniform setae; metatibial apex not distinctly enlarged and with normal setation; male metatrochanters depressed and with a central carina, with a great laminar appendix apically, bearing a tuft of setae. Last visible tergite of male abdomen slightly emarginated at middle. Last visible sternite of male abdomen as in Fig. 45. Parameres (Fig. 66) wide, short, lobes gradually narrowed; aedeagus with two subequal and spaced hooks, endophallic hook slightly angulated, curved at apex.

Taxonomic remarks. The possible synonymy of $T$. bytinskii with $T$. senilis was hypothesized by Kaszab (1958) and confirmed by Dvořák (1983) and Bologna (1988). This synonymy is supported after the examination of the types of $T$. senilis (MNHN), of a paratype of T. bytinskii, and of some additional specimens from Israel.

The species is similar to both T. flavipes and the nominate form of $T$. dives, but differs by the red male metatrochanters, the long white and dense body setation, the deep longitudinal depression of pronotum, and the pronotum puncturation with large punctures without ridges. Male genitalia as in Fig. 66

Type material. Types were not defined in the description. After the examination of some possible syntypes in MNHN, we selected a lectotype: o (MNHN, Pic coll.), with the following labels: "Syrie Akbès"; "TYPE" (white, hanwritten); "senilis Ab = eylandti Sem" (M. Pic's graphy?); "Lectotypus Lytta senilis Abeille de Perrin M. Bologna des. 1985" (red, handwritten/printed); "Teratolytta senilis (Abeille de Perrin) M. Bologna det. 1985" (white, handwritten/printed). Three other possible syntypes from "Akbès", considerably damaged by dermestid beetles, are preserved in MNHN (Abeille collection), as well as two additional specimens from the same locality (general collection). T. bytinskii Kaszab, 1957: ô holotype, + allotype and 90 and $4 \%$ paratypes: Israel, Daphne oaks, $4.1 i i .1942$ on Quercus leg. Bytinski-Salz (Bytinski-Salz coll., probably in MUH; one paratype, examined, at HNHM); one paratype Tel Aviv 21.iv, one paratype Ramat Rahel 24.i.

Distribution (Fig. 16, gray squares). Turkey: (Antiochia) Akbez (MNHN; Abeille de Perrin, 1895, loc. typ.; Escherich, 1896; Borchmann, 1917; Kaszab, 1958). Syria: Syria (Dvořák, 1983); N Syria (Mader, 1927). 45 KM NW Hama, OrontesHaupt Kanal W Acharna (CB, C.Scheuern). Israel: Israel (Kaszab, 1958 as bytinskii; Dvořák, 1983, 1996). Daphne oaks (Kaszab, 1957 as bytinskii); Tel Aviv (Kaszab, 1957 as bytinskii); Ramat Rahel (Kaszab, 1957 as bytinskii). Evolution Canyon II "south-facing slopes" and "balley bottom", Lower Nahal Keziv, W Upper Galilee $33^{\circ} 02^{\prime} \mathrm{N}-35^{\circ} 11^{\prime} \mathrm{E}$ (Finkel et al., 2002 as bytinskii); Upper Galilee (Chikatunov, 1999 as bytinskii; Finkel et al., 2002 as bytinskii); Hermon Mt. (Chikatunov, 1999 as bytinskii; Finkel et al., 2002 as bytinskii); Central Coastal Plain (Chikatunov, 1999 as bytinskii; Finkel et al., 2002 as bytinskii); Judean Hills (Chikatunov, 1999 as bytinskii; Finkel et al., 2002 as bytinskii). Erroneously reported from Iran by Dvořák (1996).

Teratolytta tricolor (Haag-Rutenberg, 1880) comb. $\mathbf{n}$.

Lytta tricolor Haag-Rutenberg, 1880: 76

Lytta dives (pars), Escherich, 1894: 280.

Teratolytta dives (pars), Borchmann, 1917: 107.
Teratolytta dives var. tricolor, Kaszab, 1958: 254.

Type locality. "Persia" (Haag-Rutenberg, 1880).

Diagnosis. Body length: 11.6-19.4 mm. Metallic green with a bronze-cupreous longitudinal stripe on the middle elytron and on genae. Maxillary and labial palpi, and legs (except metallic coxa and black trochanter) red, antennae black. Head without postocular depressions. Male metathorax with conical tubercles. Male mesotibiae markedly modified at apex (Fig. 31) with a spine-like brush of agglutinated setae on a basal protuberance; two spurs on all tibiae; male mesotarsomere I (Fig. 31) longer than wide, subtrapezoidal with black spiniform setae on inner side, II without modified setae; male metatrochanters (Fig. 53) depressed and with a central carina, with a very great laminar appendix bearing a tuft of setae only on the side of apex. Last visible tergite of male abdomen slightly emarginated at middle. Parameres (Fig. 67) wide, short, lobes gradually narrowed; aedeagus with two subequal and spaced hooks, endophallic hook slightly angulated, curved at apex.

Taxonomic remarks. Escherich (1894) and Kaszab (1958) considered "Lytta" tricolor Haag-Rutenberg, 1880 as a variety of $T$. dives. We did not examine the type of the former taxon, but only some specimens from different regions of Iran and from Buchara in Uzbekistan. Based on the following distinctive characters, we consider this taxon as a species distinct from $T$. dives: aedeagal distal hook more gibbose (Fig. 67, tricolor, and Fig. 62, dives, respectively), mesotarsomere I very enlarged at base (Fig. 31, tricolor, and Fig. 26, dives, respectively), laminar expansion of apex of mesotibiae wider (Fig. 31, tricolor, and Fig. 26, dives, respectively), metatrochanter with appendix wider and externally curved at apex, and wider also at base (Fig. 53, tricolor, and Fig. 50, dives, respectively), metatibiae more depressed internally, denser setation of fore part of body, legs longer and lighter red.

Type material. According to the description (HaagRutenberg, 1880), the types, not examined, are preserved in the Bates (probably in BMNH ) and Haag-Rutenberg (probably in the Zoologischen Sammlung des Bayerischen Staates in München) collections.

Distribution. (Fig. 18, stars). Iran: Iran (MCSN as phalerata, MCNV; Haag-Rutenberg, 1880; Escherich, 1894; Kaszab, 1958; Iablokoff-Khnzorian, 1983; as phalerata). (Gilan) Assalem (MNHN; Kaszab 1968b, as phalerata). (Mazandaran) Kelardasht (MNHN; Kaszab 1968b, as phalerata); Sari (MCSN, as phalerata). (Gorgan) Gorgan (Mirzayans, 1970, as phalerata); Astrabad (= Gorgan) (FSCA, MNHN and MCSN, PPT as phalerata sub Lytta keyserlingi Meg. and fulgurans Deyr.; MRSN, as phalerata; Escherich, 1894, as phalerata). (Golestan) Gholidagh (PPT); Gombad-kavous, Gholidagh (Mirzayans, 1970, as phalerata). (Khorassan) $120 \mathrm{~km}$ Est of Bojnurd (MNHN; Kaszab, 1968b, as phalerata). (Kermanshah) Qasr-e Shirin (Mirzayans, 1970, as phalerata); Khosravi (PPT; Mirzayans, 1970, as phalerata). (Kerman) Jiroft (PPT; Mirzayans, 1970, as phalerata). Uzbekistan: Buchara env. (CB, as phalerata). 


\section{Group eylandti}

\section{Teratolytta eylandti Semenow, 1894}

Teratolytta eylandti Semenow, 1894: 534; Borchmann, 1917: 107; Kaszab, 1958: 254; Kaszab, 1968a: 450 (pars); Dvořák, 1983: 444; Dvořák, 1996: 165.

Lytta eylandti, Escherich, 1896: 28.

Teratolytta holzschuhi Dvořák, 1983: 443, Fig. 5; Dvořák, 1996: 165 , Fig. 5. New synonymy.

Type locality. "Prov. Transcaspia: Ai-dere in montibus Kopet-dagh" (Semenow, 1894). The type locality of the synonym T. holzschuhi is: "Nord Iran, $80 \mathrm{~km}$ westlich von Bodjnurd” (Dvořák, 1983).

Diagnosis. Body length: 8.2-14.1 mm. Dark green-blue metallic, subopaque. Maxillary and labial palpi, and legs (except black coxa and trochanter) red, antennae black. Head without postocular depressions. Male metathorax with elongate oval tubercles (Figs 39-41). Male protibiae (Fig. 42) subcylindrical but depressed on inner side. Male mesotibiae modified at apex (Fig. 32) with a spine-like brush of agglutinated setae not borne on a basal protuberance; two spurs on all tibiae; mesotarsomere I (Fig. 32) longer than wide, subrectangular, without black spiniform setae on inner side, II without modified setae; metatibiae depressed on inner third, but not expanded at apex and normally setose; male metatrochanters (Fig. 54) depressed and with a central setose carina, without appendix. Last visible tergite of male abdomen slightly emarginated at middle. Parameres (Fig. 68) robust and with short lobes; aedeagus with two subequal and normally spaced hooks, proximal hook subapical in position, endophallic hook slightly angulated, curved at apex. Female external genitalia as in Fig. 77.

Taxonomic remarks. The new synonymy of $T$. holzschuhi with $T$. eylandti was confirmed by the examination of types of both taxa. Dvořák (1983) considered T. holzschuhi as distinct from T. eylandti based on Kaszab (1958), who erroneously considered the shape of trochanter of the last species as unmodified. Actually, the modification of this structure was already mentioned in the description (Semenow, 1894) and confirmed on types.

The elytral colour varies from blue to blue-green; two specimens from Kara-Kala have blue elytra and green head and prothorax.

Type material. According to the original description (Semenow, 1894) the type series, collected by K. Eylandt on 10.v.1893, includes eight males and eleven females, preserved in the P. Semenow collection (ZMAS). We examined one $\delta$ and one $q$ syntypes, but actually, the original labels indicated "10.V.1890". The syntype has the apical hook of aedeagus partially broken. T. holzschuhi: ô holotype, "Teratolytta holzschuhi sp. n., det. M. Dvořák, 81. Nord - Iran, 23.7.1974, 80 km W Bodjnurd, Steppengebiet, um 1000 m, leg. Holzschuh \& Ressl" (CD) (Dvořák, 1983). According to the description, the type material includes also a 0 paratype from the same locality, preserved in Probst's collection, but we did not find it.

Distribution (Fig. 18, spots). Turkestan (Kaszab, 1958). Uzbekistan: Karakul (C.Probst). Turkmenistan: Turkmenistan (MCNV; Reichardt, 1934; Dvořák, 1996). Transcaspia (Borchmann, 1917; Mader, 1927). Kara Kala (MGEN); Kopetdagh, Ai-dere (SMNS; Semenow, 1894, type locality;
Reichardt, 1934). Iran: Iran (Dvořák, 1996 as T. holzschuhi). (Khorasan) Bojnurd (PPT; Mirzayans, 1970); Ala Dagh (MCSN, identified as $T$. dives and $T$. eylandti); Ala Dagh Budzhnurd (CB, MRSN); Badranlou (Mirzayans, 1970).

\section{Teratolytta vanensis Kaszab, 1968}

Teratolytta vanensis Kaszab, 1968a: 448; Dvořák, 1983: 444; Dvořák, 1996: 165

Type locality. "Klein-Asien: Kusunkiran, östlich von Van" (Kaszab, 1968a). This locality was not found in the detailed maps of Turkey; the name is typically Armenian and not Turkish.

Diagnosis. Body length: $9.6 \mathrm{~mm}$. Monochromatic green metallic or with a bronze-cupreous longitudinal stripe on middle of elytron, sides of pronotum and genae. Maxillary and labial palpi, and legs (except black coxae and trochanters) red, antennae black. Head without postocular depressions. Male metathorax with elongate oval tubercles. Male protibiae subcylindrical but depressed on inner side. Male mesotibiae modified at apex (Fig. 33) with a spine-like brush of agglutinated setae not borne on a basal protuberance; two spurs on all tibiae; male mesotarsomere I (Fig. 33) longer than wide, subrectangular with black spiniform setae on inner side, II without modified setae; male metatibiae depressed on inner third, but not expanded at apex and normally setose; male metatrochanters depressed and with a central setose carina, without appendix. Last visible tergite of male abdomen slightly emarginated at middle. Last visible sternite of abdomen as in Fig. 47. Parameres (Fig. 69) slender, lobes gradually tapering, subclavate at apex; aedeagus with two subequal and broadly spaced hooks, endophallic hook slightly angulated, curved at apex.

Taxonomic remarks. A poorly known species; the single male examined from a new locality differs from the description by the elytral coloration, which is not monochromatic as in the type, but shows a longitudinal bronzecupreous stripe, and by the pronotum coloration, vaguely bronze on sides.

Type material. Holotype $\delta$, allotype $q$, one $\delta$ and $3 q$ paratypes, "Klein-Asien: Kusunkiran, östlich von Van, $2265 \mathrm{~m}$, 29.V.1966" (NHMW, HNHM) NHMW not examined; one $\delta$ paratype from "Misis, östlich von Adana, 17.IV.1966" (NHMW).

Distribution (Fig. 16, black triangle). Turkey: Uker, Hory (both names indicated on label were not identified as Turkish localities) (CB). (Adana) Misis (Kaszab, 1968a) (NHMW). (Van) Kusunkiran, East of Van (Kaszab, 1968a, loc. typ.; Dvořák, 1996) (NHMW, HNHM).

\section{Group optabilis}

\section{Teratolytta optabilis (Falderman, 1832)}

Lytta optabilis Falderman, 1832: 209, pl. 4, Fig. 6; Escherich, 1894: 282.

Teratolytta optabilis, Borchmann, 1917: 107; Kaszab, 1958: 253; Dvořák, 1996: 163.

Type locality. Lenkoran (Falderman, in Ménétriès, 1832).

Diagnosis. Body length: 10.0-20.8 mm. Monochromatic opaque metallic green, including the whole legs; mouthparts and antennae black. Head without postocular 
depressions. Male metathorax with large, oval tubercles. Male mesotibiae modified at apex (Fig. 34) with a spinelike brush of agglutinated setae not borne on a basal protuberance; two spurs on all tibiae; male mesotarsomere I (Fig. 34) longer than wide, subrectangular, ventral side not depressed, with normal setation as on mesotarsomere II; male metatibial apex not distinctly enlarged, with normal setae; male metatrochanters depressed and with a central carina, with a great laminar appendix apically bearing a tuft of setae. Last visible tergite of male abdomen obtuse in the middle. Parameres (Fig. 70) wide, short, lobes gradually narrowed; aedeagus with two subequal and very approached hooks, endophallic hook slightly angulated, curved at apex. Female external genitalia as in Fig. 78.

Taxonomic remarks. An easily distinguishable species because of the body micro-punctures and coloration. Probably close to the eylandti group according to the shape of the mesosternal tubercles.

Type material. Not indicated in the description and not examined.

Distribution (Fig. 18). Erroneously cited from Siberia as demonstrated by Escherich (1894). Russia: Caucasus (MNHN; Escherich, 1894; Borchmann, 1917; Mader, 1927; Kaszab, 1958; Dvořák, 1996). (Dagestan) Derbent (Escherich, 1894). Armenia: Armenia (MGEN). Araks (MNHN); Transcaucasia and Armenia (Iablokoff-Khnzorian, 1983). Azerbaijan: Azerbaijan (Iablokoff-Khnzorian, 1983). Maraza (CB); Zosmapen (CB); Lenkoran (Falderman, in Ménétriès, 1832; Escherich, 1894; Borchmann, 1917; Mader, 1927); Baku (Schneider \& Leder, 1878); Gandzak Valley (Schneider \& Leder, 1878). Iran: (Azerbaijan) Moghan (PPT); Kalibar, Ahar (PPT); Ardabil, Doudjagh (PPT).

AKNOWLEDGEMENTS. This study includes the results of field researches funded by the Consiglio Nazionale delle Ricerche (Gruppo Nazionale di Biologia Naturalistica; Italia/USA "Sistematica filogenetica dei Coleotteri Meloidae" project), and by the Ministero dell'Università e della Ricerca Scientifica e Tecnologica grants (former " $60 \%$ " and " $40 \%$ " funds, respectively). Research work at the Budapest, Gainesville and Paris Museums were partially facilitated by grants of the Italian Ministero dell'Università e della Ricerca Scientifica e Tecnologica and of the Center for Systematic Entomology (Gainesville). One research visit of the Sporades Islands (Greece) was carried out during the second zoological mission (1989) of the oceanographic ship Bannock of the Italian Consiglio Nazionale delle Ricerche, organized by prof. Baccio Baccetti (Siena). We wish to thank all colleagues who collaborated with one of us (MAB) in the field researches in Middle East: R. Argano, P. Audisio, C. Belfiore, M. Cobolli and C. Marangoni. We are very grateful to the following entomologists who, during the last 20 years, helped us with the loan of specimens or permitted the examination of their collections, which are listed in the paragraph of Material and methods: M.E. Bacchus (London), C. Besuchet (Genève), F. Cassola (Rome), A. Colla (Triest), M. Daccordi (Verona and Turin), H. Freude (Falconara, Ancona), P. Giachino (Turin), C. Girard (Paris), G. Gobbi (Rome), Z. Kaszab (Budapest), C. Leonardi (Milan), A. Liberto (Rome), O. Merkl (Budapest), E. Migliaccio (Rome), B. Osella (Verona and L'Aquila), J.D. Pinto (Riverside), R. Poggi (Genoa), J. Probst (Wien), L. Saltini (Modena), A. Vigna Taglianti (Rome). Special thanks are due to M. Dvorák (Praha), A.G. Kirejtshuk (Saint Petersburg), and S. Serri (Teheran) for their kind support by sending types and other interesting material, to N. Gompel, A. Teynié and Ph. Geniez (Montpellier) for the gift of several specimens of the new species T. monticola, and to Ph. Geniez also for the nice photos of this new species. P. Bombi helped us with the preparation of the maps.

\section{REFERENCES}

Abeille de Perrin E. 1895: [Description de deux nouvelles espèces de Coléoptères]. Bull. Soc. Entomol. Fr. 1895: xxiii-xxv.

Angelov P. 1964: Coleoptera aus der Thrakischen Tiefebene und einigen ansgrenzenden Gebieten. In: Die Fauna Thrakiens, Band I. Bulg. Akad. Nauk, Zool. Inst. Muz., Sofia, pp. 307-324 [in Bulgarian, German title and abstr.].

BAEVA V.G. 1959: Insect pests of stone fruit crops in the Hissar Valley. Trudy Inst. Zool. Parazitol. 19: 110 [in Russian].

Bologna M.A. 1986: Données faunistiques et zoogéographiques sur les Meloidae (Coleoptera) de Grèce. Biol. Gallo-Hellen. 12: 409-419.

Bologna M.A. 1988: Il popolamento delle aree di transizione zoogeografica: i Meloidae (Coleoptera) della regione siropalestinese. Biogeographia (n.s.) 12[1986]: 27-47.

Bologna M.A. 1991: Coleoptera: Meloidae. Fauna d'Italia. XXVIII. Calderini, Bologna, xiv + 541 pp.

Bologna M.A. 1994: I Meloidae della Grecia. Fragm. Entomol. (Suppl.) 25: 1-119.

Bologna M.A. \& Aloisi G. 1994: Systematics and bionomics of Physomeloe Reitter, with description of the first instar larva (Coleoptera: Meloidae). EOS, Rev. Esp. Entomol. 69: 45-56.

Bologna M.A. \& Di Giulio A. 2002: Review of the Southern Africa genus Prolytta Kaszab, with a description of the first instar larva, and bionomic and taxonomic remarks (Coleoptera, Meloidae). Invert. System. 16: 177-194.

Bologna M.A. \& Marangoni C. 1990: Dispersal, dispersion and phoresy in the blister beetle fauna (Coleoptera, Meloidae) of eastern Mediterranean and other islands. Accademia nazionale dei Lincei. International Symposium on "Biogeographical aspects of insularity". Atti Conv. Lincei 85: 345-366.

Bologna M.A. \& Pinto J.D. 2001: Phylogenetic studies of Meloidae (Coleoptera) with emphasis on the evolution of phoresy. System. Entomol. 26: 33-72.

Beauregard H. 1890: Les Insectes Vésicants. Félix Alcan, Paris, xvi + 544 pp., 34 pls.

Borchmann F. 1917: Pars 69: Meloidae, Cephaloidae. In Junk W. \& Schenkling S. (eds): Coleopterorum Catalogus. Junk, Berlin, pp. 1-208.

Brullé C. A. 1832: Expédition Scientifique en Morée 3 (2). Levrault, Paris, xxix + 395 pp., 22 pls.

Chikatunov V. 1999: Catalogue of the Beetles (Coleoptera) of Israel and Adjacent Areas. Department of Zoology, The George S. Wise Faculty of Life Sciences, Tel Aviv University, ii $+88 \mathrm{pp}$.

Conev I. 1958: Beitrag zur Kenntnis der Meloidenfauna Jugoslawiens. Godisn. Biolog. Inst. Sarajevo 11: 3-30 [in Serbian, German title and abstr.].

DokHTourofF W. 1890: Faune coléoptèrologique aralocaspienne. XIII partie, Méloides - Cantharides. Horae Soc. Entomol. Ros. 24: 121-192, 1 pl.

Dvoř́́K M. 1983: Drei neue Arten und einige bemerkungen zur Familie Meloidae (Coleoptera). Acta Entomol. Bohemoslov. 80: $441-450$.

Dvoř́́K M. 1996: Der Schlüssel zur Bestimmung der MeloidenGattung Teratolytta (Coleoptera: Meloidae). Klapalekiana 32: $163-165$. 
EsCHERICH K. 1894: Beiträge zur Naturgeschichte der Meloidengattung Lytta Fab. Verhandl. K. K. Zool.-Botan. Gesell. Wien 44: 251-298, 4 pls.

EsCHERICH K. 1896: Meloiden Studien. IV Theil. Wien. Entomol. Ztg. 15: 27-30.

EsCHERICH K. 1897: Zoologische Ergebnisse einer von Dr. K. Escherich und Dr. L. Kathariner nach Central-Kleinasien unternommenen Reise. IV. Theil. Coleopteren. Entomol. Z. Herausg. Entomol. Ver. Stettin 58: 1-48.

Finkel M., Chikatunov V., Nevo E. 2002: Coleoptera of "Evolution Canyon" II: Lower Nahal keziv, Western Upper Galilee, Israel. Pensoft, Sofia-Moscow, iii +270 pp.

FrivaldSZKY E. 1833-1837: Közlések a Balkány vidékén tett természettudományi utazásról. [Natural History Travel in the Balkan Region.] A Magyar Tudós Társasag Évkönyve, Pest Buda, Második Kötet, 3 Vols.

FrivalDSZKY J. 1877: Adnotationes coleopterologicae. Természet. Füz. 1: 136.

Gaubil J. 1849: Catalogue Synonymique des Coléoptères d'Europe et d'Algérie. Maison, Paris, $297 \mathrm{pp}$.

GupTA A.P. 1971: External genitalia of Meloidae (Coleoptera). II. The genitalia and their taxonomic significance. Misc. Publs. Entomol. Soc. Am. 8: 1-29.

Gupta A.P. 1978: External genitalia of Meloidae (Coleoptera) III. Significance of some genitalic components in the higher classification of the family. Dt. Entomol. Z. (N.F.) 25: $131-157$.

HaAg-Rutenberg G.J. 1880: Beiträge zur Kenntniss der Canthariden. Dt. Entomol. Z. 24: 17-90.

HAUSER F. 1894: Beitrag zur Coleopteren-Fauna von Transcaspien und Turkestan. Dt. Entomol. Z. 1894: 17-74.

HEyden L. von 1885: Beiträge zur turkestanischen ColeopterenFauna. Dt. Entomol. Z. 29: 273-298.

Heyden L. von 1888: Ueber die von L. Conradt aus dem AlaiGebirge mitgebrachten Coleopteren. XIII. Dt. Entomol. Z. 1888: $39-44$.

Heyden L. von, Reitter E. \& Weise J. 1883: Catalogus Coleopterorum Europae et Caucasi. Nicolai, Berlin, ii + 228 pp.

Heyden L. von, Reitter E. \& Weise J. 1906: Catalogus Coleopterorum Europae, Caucasi et Armeniae Rossicae. 2nd ed. Reitter, Berlin, 774 pp.

IABLOKOFF-Khnzorian S.M. 1983: Meloidae and Alleculidae. Fauna of Armenian SSR. Vol. 5. Inst. Zool., Akad. Nauk Arm. SSR, Yerevan, 155 pp. [in Russian].

ISAAKIDÉS C.A. 1935: Liste I. des insects et autres animaux nuisibles aux plantes cultivées et des insectes auxiliaires de la Grèce. Ann. Inst. Phytopathol. Benaki 1: 1-12.

Kantardjeva S. 1929: Die Arten der familie Meloidae (Coleopt.) in Bulgarien (Nach der Sammlung der Königlischen Entomologischen Station in Sofia). Trav. Soc. Bulg. Sci. Natur. 14: 17-56 [in Bulgarian, German title and abstr.].

Kaszab Z. 1956: Felemás Bogarak 3. [Heteromera 3.] Fauna Hungariae. Akadémiai Kiadó, Budapest, 108 pp. [in Hungarian].

KasZAB Z. 1957: New Meloidae (Coleoptera) from Israel. Bull. Res. Council Israel (B) 6: 229-232.

Kaszab Z. 1958: Die Meloiden Afghanistans (Coleoptera). Acta Zool. Acad. Sci. Hung. 3: 245-312.

Kaszab Z. 1959: Phylogenetische Beziehungen des Flügelgeäders Meloiden (Coleoptera), nebst Beschreibung neuer Gattungen und Arten. Acta Zool. Acad. Sci. Hung. 5: 67-114.

KASZAB Z. 1967: Ergebnisse der Albanien-Expedition 1961 des Deutschen Entomologischen Institutes. 69. Beitrag. Coleoptera: Meloidae. Beitr. Entomol. 17: 537-546.
KaSZAB Z. 1968a: Ergebnisse zoologischer Sammlreisen in der Türkey. Coleoptera: Meloidae. Ann. Naturh. Mus. Wien 72: 443-450.

KASZAB Z. 1968b: Contribution à la faune de l'Iran. 8. Coléoptères Meloidae. Ann. Soc. Entomol. Fr. (n.s.) 4: 749-776.

KASZAB Z. 1973: Beiträge zur Kenntnis der Fauna Afghanistans. Acta Mus. Morav. (Sci. Nat.) 56-57: 267-308.

KIESENwETTER E.A.H. 1861: Beiträge zur Käferfauna Griechenlands. Siebentes Stück: Tenebrionidae, Cistelidae, Lagriiariae, Pedilidae, Anthicidae, Mordellinae, Meloidae, Oedemeridae. Berlin. Entomol. Z. 1861: 221-252.

Kolov S.R. 2003. Taxonomic composition of blister-beetles (Coleoptera, Meloidae) of Kazakhstan. Tethys Entomol. Res. 8: $157-168$ [in Russian].

Kosanin N. 1904: Index Coleopterorum in Museo HistoricoNaturali Serbico. Musei Srpske Zemlje, Beograd, 26 pp. [in Serbian, Latin title].

KRYZHANOVSKiJ O.L. 1959: The key of the species Teratolytta (Coleoptera, Meloidae), inhabiting the U.S.S.R with the description of two new forms from Tadjikistan. Entomol. Oboz. 38: 855-859 [in Russian, English abstr.]).

Laporte de Castelnau F.L. 1840: Histoire Naturelle des Animaux Articulés. Duménil, Paris, 564 pp., 38 pls.

LEGAKIS A. 1990: The zoological Museum of the University of Athens. 4. The collection of Coleoptera from Greece. Part II. Biol. Gallo-Hellen. 17: 59-96.

Mader L. 1927: Meloidae. In Winkler A. (ed.): Catalogus Coleopterorum Palaearcticae. A. Winkler, Wien, pp. 851-880.

MÉNÉTRIÈs E. 1832: Catalogue raissonné des objets de zoologie recuillis dans un voyage au Caucase et jusqu'aux frontières actuelles de la Perse, entrepris par orde de S. M. l'Empereur. Académie Impériale des Sciences, St. Pétersbourg, $271+$ xxxii + iv pp.

Mirzayans H. 1970: Contribution à la connaissance de la faune des Clerides et Méloides de l'Iran. Entomol. Phytopathol. Appl. 29: 25-37.

MüLLER G. 1936: Sopra alcuni meloidi dell'isola di Coo (Egeo). Boll. Soc. Entomol. Ital. 68: 91-92.

Mulsant E. \& Rey C. 1858: Coup d'oeil sur les Insectes de la famille des Cantharidiens accompagné de la description de diverses espèces nouvelles ou peu connues. Mém. Acad. Sci. Lyon (2) 8: 122-220.

Oertzen E. VON 1886: Verzeichniss der Coleopteren Griechenlands und Cretas, nebst einigen bemerkungen über ihre geographische Verbreitung und 4 die Zeit des Vorkommens einiger Arten betreffenden Sammelberichten. Berlin. Entomol. Z. 30: 189-293.

PriPISNOVA M.G. 1987: Fauna and ecology of Meloid beetles (Coleoptera, Meloidae) in the Tadzhik SSR. Entomol. Oboz. 66: 555-571 [in Russian].

ReICHARDT A.N. 1934: Key and checklist of the Blister beetles of Turkmenia. Akad. Nauk Turkmensk. SSR. 6: 205-239 [in Russian].

ReICHE L. 1859: Synonymische Bemerkungen. III. Berlin. Entomol. Z. 1859: 84-92.

SchatzMayr A. 1943: Coleotteri raccolti dal Capitano Leonida Boldori in Albania. Atti Soc. Ital. Sci. Nat. Mus. Civ. St. Nat. Milano 82: 93-140.

SchNeIDER O. \& Leder H. 1878: Beiträge zur Kenntniss der Kaukasischen Käferfauna. Barkart, Brünn, 357 pp., 6 pls.

Semenow A. 1894: Coleoptera asiatica nova. Horae Soc. Entomol. Ros. 28: 526-547.

SEMENow A.E. 1951: Harmful entomofauna of unirrigated horticulture in Kondara. In: Ushchelye Kondara [Kondara Valley]. Moscow-Leningrad, pp. 377-400 [in Russian]. 
SNeAd J.S. \& Alcock J. 1985: Aggregation formation and assortative mating in two meloid beetles. Evolution 39: $1123-1131$.

SolSKY P. 1881-1882: New or little known beetles from the periphery of Russian Empire and adjacent countries. Trudy Ross. Entomol. Obshtsh. 12[1881]: 231-265; 13[1882]: 31-84 [in Russian].

Tо́тн L. 1973: Fundortangaben der Heteromeren (Coleoptera, Heteromera) aus dem Karpaten-Becken. Folia Entomol. Hung. (s.n.) 26: 165-192 [in Hungarian, German title and abstr.].

Turco F. \& Bologna M.A. 2005: Sexual and cleaning behaviour of Lydus trimaculatus Fabricius and remarks on the courtship of the Lyttini tribe (Coleoptera: Meloidae). Dt. Entomol. Z. 52: 131-137.

Vigna Taglianti A., Audisio P.A., Biondi M., Bologna M.A., Carpaneto G.M., De Biase A., Fattorini S., Piattella E.,
Sindaco R., Venchi A. \& Zapparoli M. 2000: A proposal for a chorotype classification of the Near East fauna, in the framework of the Western Palearctic region. Biogeographia (n.s.) 20: 31-59.

Waltl J. 1838: Beiträge zur Kenntniss der Coleopteren der Türkey. Isis 6: 449-472.

Wellman F.C. 1910a: The generic and subgeneric types of the Lyttidae (Meloidae s. Cantharidae auct.) (Col.). Can. Entomol. 42: 389-396.

Wellman F.C. 1910b: On the synonymy of the Meloidae. Dt. Entomol. Z. 1910: 22-26.

ZARIPOVA D.H. 1973: The larval description of Teratolytta pilosella tadzhika Kryzh. Fauna and Ecology of Arthropods of Tadjikistan. Dushanbe, pp. 46-49 [in Russian].

Received May 12, 2004; revised and accepted October 25, 2005 